\title{
El jerifismo marroquí en la agenda colonial española como factor de legitimidad política, control social e instrumento de propaganda en el norte de Marruecos (1912-1956)
}

Moroccan Sharifism in the Spanish Colonial Agenda as a Factor of Political Legitimacy, Social Control and Instrument of Propaganda in Northern Morocco (1912-1956)

Said EL GHAZI EL IMLAHI

Universidad de Granada

said6458785v@yahoo.fr

https://orcid.org/0000-0002-6977-857X

Recibido 03/04/2020. Revisado y aceptado para publicación 25/05/2020

Para citar este artículo: Said EL GHAZI EL IMLAHI(2020): "El jerifismo marroquí en la agenda colonial española como factor de legitimidad política, control social e instrumento de propaganda en el norte de Marruecos (1912-1956)" en Revista de Estudios Internacionales Mediterráneos, 28, pp. 136-162.

Para acceder a este artículo: https://doi.org/10.15366/reim2020.28.008

\section{Resumen}

Este artículo analiza los círculos de influencia y poder vinculados al jerifismo en el norte de Marruecos y sus interacciones con la administración colonial española en el marco de la política religiosa puesta en marcha en el protectorado español en Marruecos. Este artículo analiza el encaje de la política religiosa colonialcon la ideología nacional católica dominante en España tras el final de la guerra civil.

Palabras clave: Marruecos/islam/ colonialismo español/ jerifismo/ política religiosa/

\section{Abstract}

This article analyzes the circles of influence and power linked to Sharifism in the north of Morocco and its interactions with the Spanish colonial administration in the framework of the religious policy implemented in the Spanish Protectorate in Morocco. Thus, the paper analyzes how the colonial religious policy fitted the dominant Catholic national ideology in Spain after the end of the civil war.

Keywords: Morocco/ Islam/ Spanish colonialism/ Sharifism/ religious policy/ 


\section{Introducción}

La historia del actual Marruecos se inició, según la historiografía oficial nacionalista, con la llegada del imāmldrīsibn'Abd Allāh Al-Hasanī al país, quien huía de la persecución abbasí después de la derrota de su familia en la batalla de Fajj, cerca de la ciudad de La Meca, el 11 de junio del año 786 d.C. ${ }^{1}$ Mūlāyldrīs Idesempeñaba una función religiosa más que política. Se trataba, en realidad, de una legitimidad política basada en un abolengo religioso que daba lugar al derecho divino a ocupar el cargo de imánpor herencia profética y espiritual heredada y transmitida por el jerife Hussayn, nieto del Profeta. A diferencia de lo que instruye la historia escolar marroquí, ${ }^{2}$ la dinastía idrisí no dirigió un Estado central controlado por un rey desde Fez, sino que ésta no fue más que un centro de llamamiento religioso de una organización política que apenas sobrepasaba el sistema tribal. Sin embargo, su influencia religiosa y cultural demostró una considerable envergadura: el islam penetró en Marruecos gracias a los esfuerzos de esta dinastía. Incluso tras su desaparición como liderazgo político, el linaje idrisí ocupó un lugar privilegiado socialmente (Laroui, 2012: 180-183). Mediante esta influencia moral y religiosa, el jerifismo fue incorporado como elemento sociopolítico legitimador de la autoridad política en el país con especial intensidad a partir del siglo XVI durante la dinastía sa 'dī. ${ }^{3}$

Desde un punto de vista antropológico, se trata de un liderazgo patriarcal muy arraigado en la historia cultural marroquí que suple la separación entre la sumisión antropolátrica debida al jefe por un lado $y$, por otro, la ley islámica que mantiene la ficción de un poder delegado; un paradigma que enmarca todas las relaciones cotidianas entre padre e hijo, patrón y aprendiz, maestro y discípulo. Tal hipótesis explicala interrelación entre lo religioso y lo cultural en la configuración del "despotismo oriental" (Hammoudi 2007: 105).

Por lo cual, estudiamos esta cuestión detectando los círculos del poder jerifiano en el norte de Marruecos durante la época analizada, y su interrelación política con la administración española. Es decir, determinamos los clanes, los linajes y las taifas de prestigio jerife en el protectorado español, analizando el modo de gestión sociopolítica en dicho sistema colonial, movidos por la problemática inicial de la política religiosa del colonialismo español, ¿cómo era posible instaurar un artefacto de poder católico sobre una masa de musulmanes? Respecto al jerifismo marroquí la pregunta adquiere una especial relevancia por su relación directa con la legitimidad del poder político establecido en Marruecos desde siglos atrás, un país conocido en las fuentes históricas como el imperio jerifiano.

\footnotetext{
${ }^{1}$ Para la historia política de la dinastía idrisí, véase VERNET GINÉS, Juan (1957): Historia de Marruecos, La islamización (681-1096),Tetuán: Instituto General Franco, 1957, pp. 38-59.

${ }^{2}$ Véase, la revista electrónica del Ministerio de Asuntos Islámicos Da'wa l-Haqq, donde se publica la postura oficial de régimen marroquí en diversos campos: religión, historia, pensamiento político, asuntos de doctrina mālikī y gestión de asuntos religiosos, en el siguiente enlace:

http://www.habous.gov.ma/daouat-alhaq/. [consulta: 28 de marzo de 2020]

${ }^{3}$ Un jerife - "šariff" en árabe- es un descendiente del profeta Muḥammad a través de su hija Fāțima, esposa de "Alī. Por esta razón, las familias de jerifes o šurafā' (nobleza vinculada a la ascendencia profética), se han denominado también fatimíes o alauíes. Ser jerife implica cierto prestigio social y fama política, aunque este fenómeno no es general y depende, en primer lugar, de circunstancias históricas. En Marruecos, este concepto jugó un papel importante tanto en el sistema político como en la base de la sociedad. Véase, Šurafā'en VV. AA (1978 a): Encyclopédie de L'Islam, Brill, Leiden, L’Union Académique international, pp. 526-528.
} 


\section{El jerifismo como autoridad interlocutora del poder político colonial}

En la literatura española sobre el jerifismo marroquí producida en época colonial no se observan la misma desconfianza y prejuicios xenófobos que existía respecto a las cofradías religiosas (El Ghazi El Imlahi, 2020:289-294). Al contrario, se percibe una simpatía hacia los valores de caballerosidad medieval que los españoles vieron en las figuras de los jerifes marroquíes. Gil Torres, en un artículo publicado en la Revista Hispano Africana, advertía que la debilidad del poder jerife o su desaparición definitiva causaría una anarquía espantosa, como en el caso del Rif, donde las figuras jerifes no gozaban de un prestigio social al mismo nivel que el que tenían en la región de Yebala (Gil Torres, 1923: 111). Según esta visión, el rol de las familias jerifes era esencial en el equilibrio político de la zona. En una comparación significativa en este sentido, este autor colonial recurría al caso de Rusia que en aquel momento estaba inmersa en un periodo de gran confusión por la erosión del poder teológico de la Iglesia Ortodoxa y la autoridad del Zar, una figura que concentraba el poder político con el prestigio religioso de los derechos heredados de noble sangre aristócrata.

Debido al ideal romántico que caracteriza al nacionalismo católico español, el jerifismo era una forma de liderazgo político y social más fácil de comprender que el sistema organizativo de la confederación de tribus rifeñas o que el de las cofradías sufíes. La carga religiosa de sus figuras, el linaje noble de los jerifes y sus rasgos feudales contribuía a que fueran asociados a las estructuras feudales medievales reconociéndoseles una legitimidad social útil para la estrategia de gestión sociopolítica de la administración colonial española.

En un texto dirigido a la formación de los interventores de la Delegación de Asuntos Indígenas, el interventor de la cabila de Ben Gorfet recuperaba los valores feudales de hacía cuatro siglos atrás para explicar a los futuros funcionarios del Protectorado una realidad social en el Marruecos de la primera mitad del siglo XX. En un lenguaje patriótico medieval, el jerife era presentado como un señor feudal que pertenecía a una familia de guerreros religiosos de sangre noble y linaje de gran prestigio social. Recurriendo al imaginario medieval, la taifa jerife de los gaylānin ${ }^{4}$ era presentada como si perteneciera a una familia feudal de Europa occidental, en una comparación directa con la historia europea de la Baja Edad Media (siglos del XI al XV) (Martínez Vázquez 1950: 45-57).

En cierto modo Marruecos presentaba algunos rasgos de régimen feudal desde el siglo XVII. Sin embargo, la visión española sobre el jerifismo marroquí estuvo más influida por el imaginario histórico feudal producido por el nacionalismo español que por una lectura científica sobre la realidad social marroquí, ya que el linaje jerife en Marruecos nunca constituyó una clase social por sí misma, al existir familias jerifes en todos los niveles de la vida social. El jerifismo era más bien un complemento necesario para las figuras del poder político local, pero no era imprescindible, algo que se contradice con la experiencia histórica del feudalismo europeo. (El Ghazi El Imlahi 2020: 341-345)

Sea como fuere, la influencia ideológica del nacionalismo católico español fue solamente un factor teórico - pero no por ello menos importante - en la gestión colonial del asunto jerifiano. En el sentido más práctico de la política indígena, los españoles tomaron como modelo la experiencia de

\footnotetext{
${ }^{4}$ Para las palabras en lengua árabe he seguido, en general, el sistema de transliteración de la escuela de arabistas españoles. Sin embargo, hay algunas excepciones a esta regla. Para facilitar la lectura, he optado por emplear la toponimia usada comúnmente en el idioma español de las ciudades y lugares del norte de Marruecos como Tetuán, Larache o Alcázar. En este sentido también, se destacan nombres de cabilas, santuarios o poblados mal mencionados en la documentación colonial, con el fin de evitar dudas y confusiones los he dejado tal cual sin transliteración. Los autores marroquíes se configuran en este trabajo empleando el formato más común a nivel internacional en letras latinas como, por ejemplo, Laroui o Ibn Jaldún. Cuando me refiero a autores poco conocidos en Occidente translitero su nombre según el sistema de los arabistas españoles.
} 
Francia en la parte meridional y central del imperio marroquí y su hábil utilización del sistema tribal de los grandes caídes a través de figuras como los hermanos Madani y Thami El Glaoui, que facilitaron la rápida expansión del poder colonial francés.

Francia ha aumentado gradualmente este prestigio, utilizándolo en provecho propio, y por conducto de ellos ha llegado a dominar en todos los territorios situados entre el Um-erRbia(el río) y la frontera sahariana casi sin derramar sangre francesa, pues la mayor parte de los combates sostenidos contra los enemigos del protectorado francés han sido ganados por las jaracas indígenas de los señores feudales antes citados, y los franceses no han tenido que intervenir más que en dos momentos: la marcha de Mangin sobre Marrakech y el paso del Atlas por la columna del general Lamothe al dirigirse al país del sur con objeto de ocupar Tiznit. (Gil Torres 1923b: 131).

En las páginas de la Revista Hispano Africana, Gil Torres insistía en la necesidad de continuar con este sistema de apoyo creando figuras de poder indígena para lograr un éxito similar a los franceses en la penetración "pacífica". El motivo principal que movía a las autoridades coloniales era, por un lado, evitar los derramamientos de sangre y los grandes gastos de dinero que llevaba aparejado el sometimiento por la fuerza de las cabilas y por otro aprovechar su prestigio social convirtiendo a estas figuras en intermediarias políticas entre las cabilas y la autoridad colonial. El objetivo era claro: diluir su responsabilidad política en los errores de gestión en los asuntos indígenas protegiendo así al poder central, tanto del Majzen como de la "nación protectora". (Gil Torres 1923b: 110).En realidad, fue una política que contribuyó a reforzar el carácter tradicional de las estructuras sociales del país, obstaculizando su desarrollo natural hacia otras más modernas. Los españoles eran conscientes de las diferencias étnicas, culturales y geográficas entre su zona de influencia y la del alto Atlas del protectorado francés. En Yebala, los jerifes disponían de una gran influencia y de un prestigio social inmenso, lo que les convertía, según la visión española, en un factor de poder feudal útil para la tarea colonial.

\section{La gestión política del jerifismo en los años de la pacificación colonial (1912-1927)}

Los españoles conocían desde el inicio de la penetración colonial la importancia de la dimensión jerifiana en Marruecos. Las relaciones políticas con el jerife AḥmadRaysūnī fueron establecidas antes de la firma del convenio franco-español de noviembre de 1912. La ocupación de Arcila y Larache en 1911 fue una operación facilitada por el jerife marroquí, ${ }^{5}$ que pasaría a ocupar el puesto de bajá de Arcila, por nombramiento del Sultán Mūlāy al-Ḥasan I (1873-1894). Raysūnī había sido un personaje clave en la historia de Marruecos desde las últimas décadas del siglo XIX. Las actuaciones políticas de este jerife favorecieron la penetración española desde el desembarco de Larache un año antes del inicio formal del Protectorado. Según la prensa española, Raysūnī estaba convencido de que España era la única potencia colonial adecuada para desarrollar una labor protectora hacia Marruecos. El jerife marroquí tenía la esperanza de preservar la independencia de su región a través de una política de colaboración con los españoles. El nivel menor de recursos económicos y militares de España respecto a otras potencias coloniales debería permitirle conservar un cierto grado de autonomía en su zona de influencia política (Ortega 1922,

\footnotetext{
${ }^{5}$ En una carta que envió en fechas posteriores al general Berenguer, Raysūnī escribió: ¿Habréis olvidado lo que he hecho por vuestra nación al iniciar nuestras relaciones? ¿Habréis olvidado los servicios que os presté cuando os ayudé a ocupar Larache, Kasar El-Kabir, Azila y tantos lugares importantes más? Todo esto se llevó a cabo gracias a nuestra intervención, y sin que vuestros soldados hayan disparado un solo tiro. Ahora bien, ¿cuántos lugares de estos estaban ya ocupados por otros antes de que nuestra intervención permitiera a vuestras tropas ocuparlas sin esfuerzo y sin riesgos? (Tamsamani 1999, 145).
} 
292). La ambiciosa visión de este caudillo marroquí obligó a la autoridad colonial, desde el primer momento, a gestionar políticamente la cuestión del jerifismo. El nombramiento del Jalifa, representante del Sultán en la zona del protectorado español fue un reto relevante en este sentido, puesto que, a pesar del valor estratégico de la alianza con Raysūnī, éste no fue elegido para el cargo. En 1905, Gabriel Maura Gamazo, en su libro La cuestión marroquí según el punto de vista español, describía al jerife marroquí con estas palabras:

Ambicioso e inteligente, con el prestigio que a su calidad de jerife debía, Ahmed hubiera Ilegado a ser durante el reinado de Muley Ismael, por ejemplo, un segundo Rifi, un poderoso señor feudal de tierras por él conquistadas a los infieles, (...) en Marruecos pertenecieron a ella [a esta raza] los generales como Almanzor, los caudillos como el pachá Ahmed y los bandidos como Raisuni.(Maura Gamazo 1905).

Incluso el coronel Silvestre, que iba camino de convertirse en el enemigo histórico del jerife de Tazarut, había escrito en 1913 al primer Alto Comisario de España en Marruecos, el general Alfau, y, más tarde, al Rey de España, expresando que el nombramiento del jalifa de la zona española debía recaer en la figura de Raysūnī, "la más ilustre de los jerifes del norte marroquí". El pretexto esgrimido por García Figueras de que los españoles ignoraron al principio la importancia del linaje jerifiano de Raysūnī, no cuadra con las descripciones de este personaje en las fuentes españolas, ni antes ni después del nombramiento del jalifa en el Protectorado español (García Figueras 1955, 155-156). ${ }^{6}$ En 1923, una entrevista realizada por la prensa española presentaba al jerife de esta manera:

El nombre de cherif Muley Ahmed ben Mohamed ben Abdala el Raisune el Hassani el Alami conocido en toda la región occidental de nuestra zona de Marruecos, y pasando por Uazan, patria de chorfa, y por Chefchauan, la ciudad santa (...) El Raisuní es un noble marroquí del más limpio linaje, corre por sus venas la sangre del Profeta. ${ }^{7}$

Las autoridades coloniales no consideraron sin embargo oportuno el nombramiento del jerife más poderoso de Yebala como jalifa en su zona de influencia. Buscaban otra figura jerifiana para dotar la labor colonial española del prestigio religioso y político necesario que no tuviera aspiraciones a ejercer un poder político real. El príncipe Mūlāy al-Mahdī b. Isma'il, nieto del Sultán que había luchado contra los españoles en la Guerra de África (1859-1860), apenas conocía la zona norte y no tenía ninguna influencia entre las cabilas del Rif y la Yebala (García Figueras 1955, 157). Aun así, fue la opción escogida, aunque contribuyó a crear numerosas dificultades en la penetración española inicial en Yebalaal no satisfacer las ambiciones políticas del jerife Raysūnī (Historia de las Campañas de Marruecos 1981c, 11).

El rechazo a esta decisión es relatado por el médico español Ruiz Albeniz en los siguientes términos:

(los jerifes de Yebala) tras reírse no poco de la autoridad que les presentaba apoyada del brazo de España, juraron un pacto entre sí para no acatar nunca al representante de la dinastía Filali. Ellos, que se consideran sucesores de la rama legítima de los Edrisitas. Y el Raisuni, bajá de Arcila, Alcázar, y Caíd del Garb y Yebala, Sherif Alamita, detentador de la Baraka de Muley Abdessalam, fue el primero en prestar tal juramento de rebeldía, aunque él llevase a la ruptura con España.(Gómez Martínez 2008, 355-357).

Esta ruptura con Raysūnī, que causó la guerra de resistencia a la penetración española en la región occidental, fue en gran medida el resultado de la falta de coordinación entre los centros de

\footnotetext{
${ }^{6}$ El nombramiento del jalifa del protectorado español se produjo en abril de 1913.

7Ortega, L Manuel. "Una visita al Señor de la Montaña, cuatro días en la zona rebelde". Revista Hispano Africana, septiembre de 1922, n.우 9, p: 287.
} 
decisión política de la Legación Española en Tánger y el mando militar del coronel Silvestre. ${ }^{8}$ El primero defendía la línea política de atraer a los jefes religiosos, intentando por todos los medios organizar la visita de Raysūnī a España para cumplimentar al Rey, al considerar que sería un éxito político. El segundo era partidario de un enfrentamiento militar contra Raysūnī como respuesta a su conducta autónoma al considerarla inaceptable. En agosto de 1912, en el poblado de UladBumaisa, el coronel Silvestre abrió fuego contra la mehala jerifiana, una acción militar que carecía por completo de valor estratégico, ya que la nación protectora atacaba a las tropas del Majzen protegido. El gobierno español perdió el control en una situación de lucha abierta entre su oficial y su aliado indígena. Prescindir de Silvestre hubiera supuesto una gran pérdida para el prestigio militar español en su nueva zona de poder colonial. Por otro lado, sacrificar la alianza con Raysūnī significaba ir a la guerra. Y eso es lo que ocurrió. En marzo de 1913, el jerife abandonó Tánger y se dirigió a Tazarut, el centro de su núcleo tribal, para ponerse al frente de la yihad contra España.

Durante los primeros años del Protectorado, la política jerifiana española sufrió un serio fracaso puesto que, durante mucho tiempo, las tropas españolas quedaron atrapadas en la ciudad de Tetuán, y la influencia popular del jalifa como jerife y representante del Sultán no iba más allá de las murallas de su palacio. Una gran parte del poder político en la región de Yebala estaba en manos de la rama de los Raysūnī. La primera rebelión de las tribus yeblíes con la que tuvieron que enfrentarse los españoles en 1913 fue originada principalmente por el sentimiento religioso contrario a la presencia cristiana en Tetuán. El cabecilla de la revuelta, el jerife de Taguezart Muhammad Wuld Sĩdī al-Ḥasan, tenía una relación familiar con Raysūnī: los dos habían tomado como esposas a dos hermanas, hijas de un prestigioso jerife de Yabal Habib. ${ }^{9}$

En realidad, el jerifismo en general y los Raysūnī en particular disponían de las llaves de la penetración colonial en el norte de Marruecos. Por eso la ruptura con Raysūnīno duró mucho. Las circunstancias políticas obligaron a la Alta Comisaría a volver a negociar con el jerife, intentando corregir así los errores anteriores de la rígida política militar del coronel Silvestre, que no entendía bien el papel sociopolítico que los jerifes marroquíes tenían en la sociedad marroquí. La figura del jerife no era simplemente la de un señor feudal, sino también la de un símbolo de soberanía nacional que históricamente se había activado en los momentos de lucha contra el invasor cristiano alimentando en la cultura marroquí el imaginario de una epopeya colectiva desde el siglo XVI. Raysūnī adquirió su poder básicamente por su actuación política y guerrera desde la última década del siglo XIX ya que el estatus de jerife aportaba poco en su trayectoria en la política doméstica marroquí. ${ }^{10}$ Sin embargo, liderar la yihad contra los cristianos, le proporcionaba una

\footnotetext{
${ }^{8}$ En esta cuestión, tenemos que indicar que España no disponía en esa etapa de un organismo central responsable de la política colonial. Las Comandancias Generales de Melilla, Ceuta y Larache sufrían una doble dependencia del Gobierno en Madrid y del Ministerio de Estado y del Ministerio de la Guerra. El comandante general de Larache mantenía la relación con el Ministerio de Estado a través de la Legación de España en Tánger. Un sistema complejo y poco útil según García Figueras. Más tarde, en 1925, se creó la Dirección General de Marruecos y Colonias con el fin de unificar administrativamente la política colonial y evitar los defectos de la organización anterior (García Figueras 1955, 154). Los documentos oficiales que explican la creación de una oficina para unificar los asuntos de Marruecos pueden consultarse en (Historia de las Campañas de Marruecos. 1981d. 173-176).

${ }^{9}$ AGA. Informe MulayAbdsalam Ben Machich, Patrón de Yebala y sus descendientes. S.f. Caja (15) 81/00665.

10 En su libro sobre el jerife Raysūnī, el historiador marroquí Temsamani termina describiendo a este personaje polémico: Como ya lo hemos señalado, Raisúni aparece para muchos contemporáneos como un jefe impulsivo, orgulloso y caprichoso. Nuestras fuentes han descrito detalladamente sus actitudes veleidosas; le han seguido paso a paso en su grandeza y en su miseria. Sus intrigas y sus calumnias han impresionado a los testigos marroquíes $y$ extranjeros. Raisúni desafiaba con cinismo a sus rivales y sobresalía en intimidar a sus adversarios. Fuera lo que fuere, 
capacidad excepcional para la movilización de todas las cabilas de la región, incluso en un espacio mucho más amplio que la región de Yebala.

Según la documentación francesa, la labor de Raysūnī en la revuelta del año 1913 en Yebala no fue significativa, debido a la desconfianza de parte de la población musulmana. Los muyahidines ${ }^{11} l e$ acusaron de negociar con los españoles y de mantener un doble juego político en función de sus intereses personales. ${ }^{12}$ Sin embargo, los españoles le atribuyeron la responsabilidad de toda la actividad rebelde que se extendía por el campo de la región y amenazaba seriamente las plazas españolas recién ocupadas, como Alcazár y Larache. ${ }^{13}$

El factor religioso fue determinante en la extensión de la revuelta. El jalifa Mūlāy al-Mahdī escribió a Muhammad b. Sīdī al-Hasan para negociar una solución pacífica, pero, como señala una carta francesa, el jerife conocido como Sultán de la revuelta respondió en estos términos:

Todas las tribus están unidas y están de acuerdo en combatir a los españoles. Cuando hayamos vencido, les exigiremos la evacuación de Tetuán. No tenemos ninguna confianza en sus promesas. Ellos no son como los ingleses o como los franceses, que respetan nuestra religión y nuestras costumbres tanto en Egipto como en Argelia o Túnez. Los españoles no respetan nada y odian nuestra religión. No nos habléis nunca de paz. Nadie quiere oír esta palabra. Desde el Hauz hasta el Rif, estamos todos preparados para la guerra santa, y triunfaremos con la ayuda de Dios. ${ }^{14}$

Más allá de la credibilidad del discurso religioso, es evidente que refleja el carácter político de la revuelta que se movilizaba socialmente según la tradición religiosa de la yihad contra los infieles españoles (kufār), con los mismos prejuicios y estereotipos de las guerras medievales contra los cristianos en la península ibérica. Pese a los años de penetración económica y política, las autoridades españolas no sabían que la función social de los jerifes iba más allá de su identificación como señor feudal. En resumen, la gestión política del jerifismo durante la primera década de colonización española reflejaba un débil conocimiento científico de la estructura social del país.

Raysūnī, que de ser un bandido pasó a ser un bajá de Arcila, servía al Majzen fielmente, manteniendo el orden social después de que el Sultán le otorgara el poder. ${ }^{15}$ En los años de la ocupación colonial, realizó un peligroso doble juego político con el intento de crear un Estado

los montañeses le temían porque les gravaba con duras contribuciones. Sobra decir que nuestro hombre defendía sus derechos reales en sus sermones y en sus predicaciones cargados de versículos coránicos. Ejercía una verdadera tiranía y actuaba como el auténtico "Sultán de los Yebala". Era un símbolo de terror y de pánico. Nuestro hombre sigue suscitando una viva controversia y es objeto de varios panegíricos y panfletos. (Tamsamani Khallouk 1999, 145).

${ }^{11} \mathrm{El}$ término "muyahidines" hace referencia en nuestro contexto histórico del colonialismo español en el norte de Marruecos (1912-1927), a la resistencia armada de las cabilas marroquíes, un concepto totalmente diferente al significado contemporáneo de la palabra, frecuente en los medios de comunicación desde los años 80 durante la Guerra de Afganistán.

${ }^{12}$ En una carta del vicecónsul de Francia en Larache H. Martín enviada a la agencia de Tánger, el 16 de agosto de 1913 : (...) los Yebala confían poco en Raisuní al que acusan con razón o sin ella de hacer un doble juego y de negociar actualmente con los españoles. NS Maroc 125, p: 62. Citada en (Tamsamani 1999, 87).

${ }^{13}$ Para García Figueras: Yebala se había agitado ante la presencia de los cristianos en Tetuán; una haraca mandada por el cherif de Taguezart, Mohamed Uld Si Lahsen, que tenía como jalifa a Hamido el Harras, se había establecido en Ben Karrich, pero la rebeldía adquiriría todo su desarrollo cuando se pusiera al frente de ella El Raisuní (...). (García Figueras 1955, 165).

${ }^{14}$ Carta del gerente de la Agencia y del consulado general de Francia en Tánger a Paris, 8 de agosto de 1913, NS Maroc 126, p: 20,21. (Tamsamani1999, 89).

${ }^{15}$ Según la biografía deRaysūnī, escrita por su amiga Rosita Forbes, viajera y escritora inglesa, el jerife impuso su nombramiento como bajá del Fahes al Majzen a través de una larga lucha armada y el secuestro de extranjeros. Su dominio aumentaba a costa de leyendas de sus poderes sobrenaturales. Al poco tiempo de ser investido en sus funciones de caíd el 18 de junio de 1904, el orden y la seguridad volvieron a reinar en todo el país de Yebala. El jerife se proclamó un servidor de la autoridad legal (Forbes 2010, 41-69). 
dentro del Estado. Como señala la documentación francesa, ${ }^{16}$ Raysūnī mantenía relaciones con los alemanes desde 1902. Fueron ellos los primeros en aconsejarle ayudar a los españoles en la ocupación de la región occidental de Marruecos. La presencia de un gobierno europeo en la zona era considerada una garantía de seguridad para los intereses económicos alemanes. En un contexto internacional inestable, Raysūnī no cesó de jugar políticamente con todos los bandos. Él mismo decía sobre su actitud: Los bereberes son mis servidores, los españoles mis esclavos, los franceses mis enemigos. Los alemanes son mis aliados (Forbes 2010, 124).

Por lo tanto, la estructura social de Yebala se desgarró entre los partidarios de WuldSīdī I-Ḥasan, enemigos de España, y las tribus sometidas a Raysūnī, que acrecentó su poder a través de una política ambigua hacia los españoles: ora predicaba la guerra santa, ora negociaba un acuerdo. Entre 1915, el año en el que firmó una tregua con el general jordana, ${ }^{17}$ y 1919 , cuando Berenguer le declaró oficialmente fuera de la ley y confiscó sus bienes, ${ }^{18}$ Raysūnī extendió su poder hasta las lejanas riberas del río Uarga y creó su propio "caidato". En este contexto, incluso durante la guerra, la actuación política era necesaria. Para contrarrestar la dimensión religiosa utilizada por Raysūnī para legitimar su oposición a los españoles el ejército colonial incorporó a sus filas a las mehalas jalifianas, integradas por soldados musulmanes, defendiendo el argumento de que no se trataba de una guerra contrala población musulmana, sino contra Raysūnī, quien no había respetado la obligación de todo buen musulmán de someterse a la autoridad del Sultán en su condición de Comendador de los creyentes acatando la autoridad de su delegado en la zona norte, el Jalifa. Para las autoridades españolas la guerra santa solo podía proclamarse contra el jerife rebelde (Historia de las Campañas de Marruecos1981c, 12). Además de la vertiente militar el enfrentamiento era un combate por el prestigio ya que el bando que lograra elaborar un discurso religioso-político de más credibilidad entre las cabilas dispondría de una posición más fuerte.

En julio de 1921, los españoles ya habían acorralado a Raysūnī en su propio territorio de influencia, pero la baraka no abandonó aún al jerife de Yebala. La derrota de Annual hizo cambiar radicalmente los planes militares del general Berenguer, y durante el mandato del general Burguete en la Alta Comisaría de España en Marruecos (1922-1923), la alianza con Raysūnī volvía a ser el quid de la política colonial española, con el fin de concentrar el esfuerzo militar español en las montañas rifeñas y contrarrestar la ofensiva imparable de 'Abd al-Karīm (Villanueva Faprón 2018, 161-162). Este nuevo pacto entre el Sultán de Yebala y los españoles fue importante desde el punto de vista militar, puesto que Primo de Rivera elaboró entonces un plan militar denominado semi-abandono que consistía en evacuar los territorios que no estaban definitivamente sometidos al poderío español. En este contexto, Raysūnī recuperó casi todo el control sobre la región occidental, incluso la ciudad de Chauen, que fue abandonada el 7 de noviembre de $1924 .{ }^{19}$

Bajo estas circunstancias, el tejido social marroquí en el norte se encontraba más segmentado que nunca, ya no sólo por las divisiones tribales y étnicas tradicionales, sino también por las divisiones políticas causadas por la intervención colonial. En el contexto de rivalidad por el liderazgo entre Raysūnī y 'Abd al-Karīm, ambas figuras explotaron su condición de jerife y ulema respectivamente

\footnotetext{
${ }^{16}$ Carta del gerente de la Agencia y del Consulado General de Francia en Tánger al Ministro de Asuntos Exteriores en Paris, el 20 de octubre de 1913. (Forbes 2010, 107-108).

${ }^{17}$ Véase el texto completo del pacto con Raysūnī (Historia de las Campañas de Marruecos 1981c, 309-312).

${ }^{18}$ En virtud del dahír 5 de julio de 1919 (Tamsamani 1999, 133).

${ }^{19}$ El texto de este pacto fue secreto, pero la prensa española publicó largos extractos de él. Véase Correspondencia de España, 22 de septiembre de 1922, no 23399.
} 
en la búsqueda de respaldos. 'Abd al-Karīm logró atraer a su causa a un jerife de Beni Aros, Mūlāy Aḥmad al-Bakkār, quien consiguió levantar contra su rival varias cabilas como las deAnyera, Bani Said y Bani Hassan. Por otro lado, los darqāwa, tanto los ḥarrāqiyyīn de Tetuán, aliados de los españoles, como los șiddīqiyyīn de Tánger, ${ }^{20}$ maniobraban en contra tanto del jerife Raysūnī como de la revuelta rifeña liderada por 'Abd al-Karīm, movidos por intereses cambiantes y contradictorios entre sí en un complejo panorama político típico de una sociedad en crisis (Villanueva Faprón 2018, 160).

Según estos datos, el jerifismo ya no funcionaba como forma de representación nacional, sino como un factor político de carácter más personal que colectivo. Los jerifes dejaron de ser árbitros sociales entre las cabilas, y pasaron a formar parte del conflicto político. La sociedad marroquí estaba atravesada por divisiones internas y no sólo por la presión colonial extranjera, como dirían más tarde los nacionalistas marroquíes. Reforzar el carácter tradicional de la sociedad a través del uso de la religión como aparato político no significaba crearloex-novo. El jerifismo, como las cofradías, era uno de los fundamentos de la sociedad marroquí, que estaba dividida y no disponía de una estructura social adecuada para actuar contra la invasión extranjera de forma colectiva.

La estrategia española en la Guerra del Rif utilizó el jerifismoraisuniano contra el liderazgo políticoreligioso de 'Abd al-Karīm como ulema y cadí. En otras palabras, enfrentó, o por lo menos pretendió hacerlo a dos ámbitos del Islam marroquí: el Islam popular del campo contra el Islam culto institucional de la ciudad. Los españoles no entendieron el carácter complementario de estas dos formas de religiosidad marroquí; en el caso de que los ulemas y los jerifes hubieran tenido enemistad, no habría sido por motivos religiosos, sino por razones políticas (El Ghazi El Imlahi 2020, 77-113). ${ }^{21}$

En esta relevante cuestión, la política religiosa del protectorado español todavía era ambigua en cuanto a la gestión del jerifismo marroquí. Tras la muerte de Mūlāy al-Mahdī, en octubre de 1923, Raysūnī había manifestado en un telegrama enviado a Madrid un mes antes su apoyo completo a la dictadura de Primo de Rivera y a su directorio militar. ${ }^{22}$ Incluso en la Liga africanista de Octubre de 1923, Manuel Ortega advertía a los reunidos que debían aprender de la experiencia considerando que cualquier nombramiento, por muy jerife que fuese en quien recayese el nombramiento, no serviría de ningún modo a los intereses coloniales de España si el elegido no gozaba de una autoridad real sobre las cabilas. De lo contrario, el poder del jalifa no iría más allá de las murallas de su palacio, y España estaría obligada a proteger a una autoridad ficticia. ${ }^{23}$

Sin embargo, el gobierno del general Primo de Rivera demoró dos años la designación de un nuevo jalifa, al considerar que Raysūnīno reunía las condiciones personales suficientes para el puesto, una decisión cuyas razones políticas no conocemos a ciencia cierta. ${ }^{24}$ En esas circunstancias, la situación delicada del protectorado exigía un nombramiento para contener la revolución rifeña a través de una figura jerife bien situada en las altas esferas del Protectorado. A nuestro juicio, fue

\footnotetext{
${ }^{20}$ Los harrāqiyyīn, así como, los șiddīqiyyīn, son las dos alas de la cofradía Darqāwiyya en el Norte de Marruecos, y nunca actuaban de mutuo acuerdo, las dos zagüías tuvieron agendas políticastotalmente distintas, por lo tanto, hablar de la cofradía como bloque político no corresponde a la realidad histórica. (El Ghazi El Imlahi 2020, 277-284).

${ }^{21}$ Es un punto esencial de la política colonial española. Se trata de la misma visión que iba a repetirse en los años cuarenta y cincuenta con la política de apoyo a las cofradías en contra de la salafiyyawațaniyyao reformismo nacionalista, bajo el lema de la tradición contra la innovación, y que tampoco funcionó. Los europeos en general no entendieron el sincretismo religioso existente dentro del Islam como concepto histórico que puede cambiar siempre según las circunstancias sociales y políticas, en contraposición con el concepto del credo religioso musulmán teóricamente fijo y establecido dentro de la ortodoxia suní o de cualquier otra doctrina practicada en el mundo musulmán.

${ }^{22}$ Revista Hispano Africana,septiembre de 1923,n ㅇ 9, p. 281.

${ }^{23}$ Revista Hispano Africana, noviembre-diciembre de 1923, n ․, pp. 519-525.

${ }^{24}$ El cargo estaba vacante desde el mes de octubre de 1923 y acabó recayendo en el hijo del anterior, Mūlāy al-Ḥasan b. al-Mahdī, quien fue nombrado jalifa en noviembre de 1925, dos meses después del desembarco de Alhucemas (Historia de las Campañas de Marruecos 1981d, 3).
} 
una estrategia que hubiera podido funcionar bien, en base a la experiencia histórica de Raysūnī con el Majzen. Sin embargo, los españoles prefirieron buscar alternativas antes que tomar una decisión política definitiva en el tiempo adecuado. ${ }^{25}$

El resultado fue previsible: Raysūnī, ya de edad avanzada, agotado por tanto juego político en todos los frentes, no podía luchar contra un líder revolucionario como 'Abd al-Karīmque tenía un proyecto republicano innovador sin antecedentes en la historia de Marruecos. El 26 de enero de 1925, un ejército rifeño encabezado por el caíd AḥmadJeriro puso fin al episodio del jerife de Yebala, capturando a Raysūnī en su propia sede de Tazarut. Murió pocos días después por causas naturales, pero la cuestión del jerifismo marroquí se mantendría abierta en la agenda política durante toda la época colonial (Tamsamani1999, 143-144).

\section{La gestión social del jerifismo y los intentos de construir un statu quo pro español (1927-1939)}

El jerifismo era una parte esencial del liderazgo social en Marruecos configurándose como una estructura de élite que mantenía el orden social y distribuía la riqueza a través de una red de clientelismo sociopolítico reconocido tanto por el poder central del Majzen como por las esferas de la autoridad local de las cabilas. El estatus social estaba constituido, en primer lugar, por valores de origen y distinción. La procedencia social es un factor fundamental en la ubicación jerárquica. La distinción, según Pierre Bourdieu, es la distancia cultural en los hábitos que establecen unos grupos sociales con otros. Además, las estrategias reproductivas de la élite están basadas en el parentesco familiar, a través de las alianzas matrimoniales que conservan e incrementan su patrimonio. El uso del término "linaje" para designar las redes cerradas del parentesco de sangre noble parece oportuno, sobre todo en nuestro caso del jerifismo marroquí, que reunía parcialmente las condiciones de una nobleza religiosa según esta definición antropológica (González Alcantud 1988, 122-124).

Los españoles estaban obligados a gestionar socialmente la cuestión jerife, sobre todo en Yebala, donde gozaba de un gran arraigo social. La naturaleza igualitaria de las confederaciones tribales rifeñas y sus asambleas representativas habían disminuido notablemente la importancia del jerifismo como fuente principal de liderazgo social en esta región (Hart 2006, 16-17), aunque los imrabdhen eran las únicas genealogías verdaderas que poseían los rifeños. ${ }^{26}$ Especialmente las taifas idrisíes, eran linajes que en algunos casos formaban facciones enteras de tribus (Hart 1997, 26-28).

Pero se trataba de un fenómeno limitado comparado con la estructura social de Yebala, donde las tres partes de los habitantes de la cabila de Beni Aros, por ejemplo, disponían de la condición de jerife. $^{27}$

\footnotetext{
${ }^{25}$ Raysūnī, fue nombrado oficialmente por la Alta Comisaría jefe de los jerifes raysūniyyīn. Los cambios en el Directorio de Primo de Rivera en septiembre de 1923 reforzaron el ala raisunista de Clemente Cerdeira, Zugasti y Castro Girona en la administración del Protectorado, que había optado desde siempre por la estrategia de un gobierno indirecto con cierta autonomía local para evitar la dispersión del poder. Las autoridades coloniales llegaron a prometer al jerife el puesto del bajalato de Tetuán. En un acuerdo secreto en la primavera de 1924 le aseguraron que ese cargo equivalía a los poderes del jalifa, pero esta alternativa no era suficiente para resolver la situación crítica en la que se encontraba Raysūnī, cuyo poder simbólico en aquella época se había debilitado. Además, le surgió oposición en Yebala.Sobre el ala raisunista en la administración colonial española véase, (Zarrouk 2017, 40-49).

${ }^{26}$ Los rifeños no distinguían entre los linajes jerifes y otras genealogías de santidad religiosa, pero sin origen jerifiano, por lo tanto, en el Rif sedomina todas estas categorías con el término imrabhen, derivado de la palabra árabe ribāț.

${ }^{27}$ AGA. Escrito del jefe de la Oficina Central de la Inspección de Larache dirigido a la IGITJ. 27 de noviembre de 1927. Caja (15) 13.01. 81/00664.
} 
La tarea administrativa de gestión del jerifismo empezó antes de terminar la Guerra del Rif (19211927). En abril de 1923 el Gran visir Ibn 'Azūz escribió una carta a las autoridades españolas pidiendo autorización para promulgar los dahíres jerifianos en nombre del jalifa de Tetuán. ${ }^{28}$ Unos años más tarde, los sobrinos del jerife lbn al-ḤasanSī 'Alī Ḥassūn, en el Rif, se dirigieron a Tetuán para renovar los dahíres jerifianos que les habían sido concedidos por los sultanes desde siglos atrás. ${ }^{29}$ Las autoridades coloniales accedieron en febrero de 1928 a esta petición aunque limitaron el alcance de dicha decisión al hacerlo con carácter puramente honorífico sin eximirles del cumplimento de las obligaciones impuestas por ley a los demás indígenas: asistencia en harakas, ${ }^{30}$ pagar los tributos personales, $t w i \bar{z} a^{31}$ y servicios de convoy. ${ }^{32}$ Los privilegios de la época precolonial habían terminado ya que el nuevo Estado del protectorado no distinguía entre sus súbditos. Pero, aun así, este carácter honorífico no podía ser neutral, aislado de todo tipo de privilegio social o económico ya que entonces, ¿qué función tendría dentro de la sociedad marroquí bajo el dominio colonial?

En realidad, los jerifes del norte marroquí mantuvieron su superioridad social y las relaciones de poder no sufrieron ningún cambio dentro del tejido social autóctono; el cambio real se produjo a nivel político en las altas esferas del régimen del Protectorado. Los jerifes marroquíes tuvieron que negociar las nuevas relaciones de caciquismo político - el fenómeno que vamos a analizar más tarde - con las autoridades coloniales. A pesar de su importancia social, aceptaron las nuevas condiciones del Estado moderno, y la más importante de ellas fue la de no tocar de ningún modo el "equilibrio calculatorio" de la zona norte. ${ }^{33}$ Las autoridades coloniales actuaban muy cuidadosamente en el terreno tribal marroquí y tenían una sensibilidad excepcional para lo que en los textos de la administración colonial se denominaba como la "buena marcha política de la cabila". La Inspección General de Intervención y Tropas Jalifianas (IGITJ) resumía la política colonial a este respecto en los siguientes términos:

No es conveniente bajo ningún concepto que se cree un estado de excepción para este indígena - se refiere al jerife Ḥasan b. Raysūnī- ni para ningún otro que pueda poner en peligro la buena marcha política de esta cabila. Todas estas autoridades guardan, como siempre lo han venido haciendo, los debidos respetos a los chorfas por su cualidad de tales, pero no pueden admitir que, valiéndose de tal condición, se propasen en sus derechos, con manifiesto perjuicio para el buen gobierno del país y prestigio de la autoridad superior que representan (...). ${ }^{34}$

El jerife mencionado en el texto era Ḥasan b. Raysūnī, que se enfrentó a otros jefes religiosos por el liderazgo de la zagüía de Sīdī Muhammad b. 'Alī de Tazarut. En concreto, estos eran Sīdī Muḥammad b. Bašīr y Sīdī Muḥammad b. Makkī, herederos directos de la zagüía. El jefe de la Oficina Central de Intervención de Larache pidió que se obstaculizara su regreso a la cabila y se

\footnotetext{
${ }^{28}$ AGA. Escrito del Gran visir Ben Azuz redactado en abril 1923. Tetuán. Caja (15) 13.01. 81/00664.

${ }^{29}$ AGA. Telegrama oficial de la IGITJ a la Central de Intervención de Melilla. 8 de febrero de 1928. Tetuán. Caja (15) 13.01. 81/00664.

${ }^{30}$ Movimientos militares del Sultán para someter a las tribus, en este caso las ḥarakas se organizaron en nombre del jalifa, lugarteniente del Sultán de Marruecos.

${ }^{31}$ Actividades colectivas de solidaridad.

${ }^{32}$ AGA. Escrito de la Central de Melilla dirigida a la IGITJ. 14 de febrero de 1928. Caja (15) 13.01. 81/00664.

${ }^{33}$ Usamos este concepto de la antropología política para demostrar la fragilidad del statu quo colonial. Los españoles temían perder el control social de su zona de influencia, por eso reforzaron las estructuras de la intermediación religiosa. En este contexto, la religión constituye un instrumento básico para la legitimidad y la continuidad del clientelismo, lo que genera un tipo de equilibrio político frágil entre los factores políticos. En este sistema, el control directo por parte de la autoridad dominante es fundamental para proteger la estabilidad y el equilibrio del poder político (González Alcantud 1997, 37-40).

${ }^{34}$ AGA. Carta del Inspector General de Intervenciones y Tropas Jalifianas enviada al jefe de la Central de Larache. 20 de enero de 1928. Tetuán. Caja (15) 13.01. 81/00664.
} 
quedara en Tetuán. ${ }^{35}$ La petición fue aceptada por la IGITJ, que apoyaba claramente su expulsión de su cabila, y establecía como norma política el empleo de mano dura contra cualquier otro jerife que tuviera las mismas aspiraciones políticas de romper el orden social y el equilibrio político establecido por las autoridades coloniales. ${ }^{36}$

En realidad, el conflicto en el seno de la cabila de Beni Said de Larache era mucho más profundo que la competencia por la tutela de una zagüía. El clan de los Raysūnī, liderados por HasanRaysūnī - antiguo jefe del Majzen raisuniano -, quería recuperar su poder tradicional en la zona, apoyado por el Gran visir Ibn 'Azūz y notables relevantes de Tetuán, y por eso declaró la guerra contra los Wulād al-Baqqāl y el caídde Beni Said, Sīdī Muḥammad b. 'Abd al-Salām al-Baqqālī, que pertenecía a esta rama. Las rivalidades entre las dos ramas jerifianas tuvieron proyección internacional, puesto que el jefe de la rama Raysūnī envió a su primo Sīdī Muḥammad b. 'Amḥad a Tánger para solicitar oficialmente la protección consular de la delegación Italiana. A pesar de que los italianos no le hicieron caso, los españoles vieron con malos ojos esta actitud inaceptable, que dejaba España en ridículo ante las potencias mundiales representadas diplomáticamente en la ciudad internacional.

El jerife fue condenado en virtud de una orden de busca y captura por actuar en contra de los intereses de la nación protectora. ${ }^{37}$ En el contexto de proteger el statu quo del protectorado español, los jerifes perdieron toda la libertad de actuación política que habían tenido en el Marruecos precolonial. El nuevo Majzen colonial, dotado con las herramientas militares, administrativas y políticas del Estado moderno europeo, dominó la gestión territorial de la zona, y estableció unas nuevas relaciones con el liderazgo social de las cabilas del norte marroquí.

Con la instalación del control militar, la Oficina de Intervención se convirtió en una institución de gobierno indirecto, que supervisaba la acción de las autoridades locales políticas, judiciales y económicas. Se encargaba de recoger los nuevos impuestos (tartīb y el impuesto del zoco); de la organización de la propiedad y de realizar estadísticas demográficas, etc. Este estilo de gobierno moderno, desconocido hasta entonces en la sociedad marroquí, no buscaba sólo realizar una gestión administrativa, sino también hacer visible la nueva autoridad del Estado a una población local acostumbrada desde siglos a someterse únicamente al poder tribal (Mateo Dieste2002, 120).

Los marroquíes de aquella época que vivían en las cabilas más pequeñas, experimentaban una transformación radical del poder. La diferencia entre el Majzen precolonial y su homólogo colonial fue muy nítida. El primero no era más que una autoridad superior separada totalmente de la estructura social (El Ghazi El Imlahi 2020, 77-113). Mientras que el antiguo sistema no era capaz de controlar las cabilas, el Majzen colonial llegó a controlar a los individuos mediante las tarjetas de identidad que contenían datos sobre su edad, estado civil y nacionalidad. Ello supuso un cambio radical en el orden social de las cabilas. Era la primera vez en la historia en la que el marroquí se identificaba ante el Estado. Fue el fin de la cabila como una unidad política.

El nuevo Estado colonial iba produciendo, con el avance de sus políticas indígenas, otras instituciones de intermediación sociopolítica. Las autoridades españolas, en contra de su ideología de gobierno indirecto, habían roto una costumbre social establecida entre las taifas de los jerifes marroquíes por motivos puramente políticos. El jefe de la Intervención de Larache consideraba

\footnotetext{
${ }^{35}$ AGA. Escrito elevado a la Inspección General por la Central de Larache. Caja (15) 13.01. 81/00664.

${ }^{36}$ AGA. Carta del Inspector General de Intervenciones y Tropas Jalifianas enviada al jefe de la Central de Larache. 20 de enero de 1928. Tetuán. Caja (15) 13.01. 81/00664.

${ }^{37}$ AGA. Información confidencial del Sector de Intervención de Xauen enviada a la IGITJ. 19 de agosto de 1928. Caja (15) 13.01. 81/00664.
} 
inoportuno el nombramiento de un naqīb de los jerifes del santuario de Mūlāy 'Abd al-Salām, ${ }^{38}$ según las nuevas condiciones de paz social que acaban de establecerse después de la Guerra del Rif (1921-1927). Esta autoridad colonial lo justificaba con el argumento de que los jerifes constituían una nobleza religiosa que siempre creía en su derecho a gobernar a los demás. Al agruparse bajo el mando de un naqīb, podrían pensar que estaban en condiciones de escapar de la autoridad de la Intervención colonial e incluso de la del Majzen. Según esta visión, nombrar un naqīb era una tarea peligrosa que causaría un riesgo real y que debía evitarse, ya que podría ser interpretada como una señal política para recuperar la tradición autónoma de los jerifes con respecto a las autoridades del gobierno. Además, la Intervención de Larache proponía que se encargara al caíd de Beni Aros, descendiente también del santo de Yebala, para que ejerciera las funciones de un naqīb al-šurafä' (naqīb de los jerifes), sin ningún otro nombramiento innecesario. ${ }^{39}$

Sin embargo, a pesar de todas estas limitaciones al papel político del jerifismo marroquí, este tipo de liderazgo mantenía su estatus en la jerarquía social. Los españoles no pretendían de ningún modo eliminar su influencia, sino integrarla dentro del sistema político de un Estado autoritario y centralizado. En este sentido, la administración española participó directamente en la gestión de asuntos de pura naturaleza jerifiana, como el conflicto entre las genealogías jerifianas y el reparto de las limosnas de los santuarios. La figura del jerife como un líder político era importante en el sistema de gobierno indirecto colonial en la sociedad marroquí. Someter a los jerifes a la voluntad del poder dominante no significaba convertirlos en ciudadanos en pie de igualdad con el resto de la población, sino en una especie de autoridad intermediaria entre los indígenas y los colonos, una figura de influencia en la sociedad incorporada al régimen colonial y que formaba parte de sus redes de clientelismo social.

Este planteamiento dispone de su principal argumento en la cuestión del reparto de las limosnas del santuario de Mūlāy 'Abd al-Salām. El conflicto entre las tribus de Sumata y Beni Aros había llegado hasta la agresión a mano armada en muchas ocasiones. Entre las dos cabilas ocurrió un altercado sangriento en el santuario y hubo que lamentar muertos por ambas partes. En 1929, la cabila de Sumata presentó una declaración a las autoridades españolas sobre este asunto. El Interventor regional, Eleuterio Peña, ejerció una intervención exitosa al poner de acuerdo a los jerifes de las dos cabilas. El convenio fue el siguiente: se nombraron dos muqadmīn (agente de autoridad a nivel de barrio o cabila) de Sumata y otros dos de Beni Aros, los cuales recogerían y guardarían la caja de las limosnas, y cada cuatro meses se realizaría el reparto de este dinero, recibiéndolo únicamente aquellos que se presentaran allí el día señalado. Esta manera de reparto no duró mucho debido a las deslealtades de algunos muqadmīn. Las autoridades del Majzendecidieron depositar las llaves de la caja de las limosnas en la Oficina de Intervención y anunciar el reparto en los zocos para que acudiera el mayor número posible de los jerifes. ${ }^{40}$

La costumbre que existía antes de la ocupación colonial era que el primer jerife que llegara cogiera lo que se había depositado en el santuario de regalos y limosnas, un modo de reparto beneficioso únicamente para aquellos que vivían en las proximidades del santuario. El protectorado quería ampliar este mercado religioso para integrar en el sistema político el mayor número posible de las familias jerifes de la zona. El inspector de la Intervención militar ordenó en diciembre de 1932 a la Central de Yebala que investigase la colocación de un cepillo en el santuario de Mūlāy 'Abd alSalām por parte del caíd de Beni Aros con el fin de recaudar limosnas de los peregrinos. La

\footnotetext{
${ }^{38}$ Naqīb de los jerifes es una especie de autoridad honorífica de carácter representativo ejerce la función de mediador entre el Majzen y las familias jerifes.

${ }^{39}$ AGA. Escrito del jefe de la Oficina Central de la Inspección de Larache dirigido a la IGITJ. 27 de noviembre 1927. Caja (15) 13.01. 81/00664.

${ }^{40}$ AGA. Informe del Interventor regional de Yebala Central sobre colocación de un cepillo en MulayAbdsalam por el Kaid de Beni Arós dirigido al Inspector de Intervenciones militares y Fuerzas Jalifianas. Tetuán. 12 de diciembre 1932. Caja (15) 13.1.81/00703.
} 
autoridad española estimaba que estas limosnas eran un derecho heredado por todos los descendientes del santo y no sólo por los jerifes de la cabila de Beni Aros, ${ }^{41}$ ya que, bajo el poder central del Protectorado, el funcionamiento político del sistema obligaba a las autoridades a unificar el trato de los individuos de la misma clase social. Los oficiales de la Intervención querían hacer ver a los jerifes y los demás indígenas que el "desorden" y la "anarquía" de la época anterior había terminado.

Así pues, convirtieron el asunto de las limosnas del santuario de Yebala en una cuestión de pura naturaleza política, ejerciendo una labor gestora de la rentabilidad del espacio sagrado de los montañeses. En presencia de autoridades españolas y marroquíes, los jerifes procedentes de diversos puntos de Yebala recibían los atributos que les correspondían, dependiendo de la cantidad depositada en el santuario. En enero de 1932, la Central de Larache hizo saber a las autoridades de Tetuán que el reparto de las limosnas entre los jerifes 'alamiyyīn de Beni Aros y raḥmūniyyīn de la cabila de Ajmasse había realizado bajo su control sin registrar ningún incidente. Este acto, que tuvo lugar el primer viernes de Ramadán, se efectuó según los acuerdos de Sidi Ali, establecidos anteriormente en abril de 1931, resumidos en la siguiente cita:

(...) se reunieron en el Jemis de Beni Arós los xorfaalamien en número de ciento ochenta y cinco hombres, y respecto al reparto de las limosnas acordaron lo siguiente: nombrar dos makadmiin para que sean los encargados de cuidar a todas las ofrendas, y un Imam que dirija los rezos, el cual también estará encargado de conservar los objetos ofrendados hasta que sean subastados. Estará también encargado de la venta de todas las reses sacrificadas y de recoger su importe cada día, además de realizar las cuentas de los salarios de él y de los dos makadmin y fakih de ramadán, cuyo importe será de 100 duros hasaníes a cada uno de ellos por cada año. Igualmente, quedaron de acuerdo en que la llave (del cepillo de limosnas) habría de quedar depositada en poder del mokadem de la zawiya de sidiheddi, y en que el reparto de lo recaudado se efectuaría tres veces al año en los días siguientes: el primer viernes del mes de moharam, el primer viernes del mes de yemadaula y el primer viernes de ramadán. Para hombres y mujeres. 3 de abril de 1931. firma de los udul (...) y de ello doy fe, Interventor Cristóbal Pérez, 7 de abril $1931 .^{42}$

La cantidad recaudada ascendió a 10.475 pesetas hasaníes, distribuida entre los 2283 jerifes y jerifas asistentes al acto, correspondiendo a cada individuo 4,58 pesetas hassaníes. ${ }^{43}$ Como era lógico, esta forma de reparto disminuía notablemente las cantidades de dinero que beneficiaban tradicionalmente a los jerifes de Beni Aros. En el siguiente reparto, que tuvo lugar en el 13 de mayo de 1932, los jerifes solamente cobrarían dos pesetas hassaníes. ${ }^{44}$

Desde febrero de 1931, la Oficina de Información de Succan, el pueblo más cercano al santuario, recibió protestas por parte de un grupo de los jerifes 'alamiyyīn del poblado por la cantidad insuficiente que recibían de las limosnas, que era el único ingreso del que disponían para vivir, y pedían la vuelta al reparto diario anterior, ${ }^{45}$ lo cual era imposible dado el acuerdo de Sidi Ali antes

\footnotetext{
${ }^{41}$ AGA. Escrito del Inspector de Intervención militar y Fuerzas Jalifianas al interventor regional de Yebala Central. 1 de diciembre de 1932. Tetuán. Caja (15) 13.1.81/00703.

${ }^{42}$ AGA. Traducción del acta de la reunión de la oficina de Sidi Ali. 7 de abril de 1931. Caja (15) 13.01.81/00664.

${ }^{43}$ AGA. Despacho de la Central de Larache dirigido a la IGITJ firmado por el teniente coronel Eleuterio Peña. 16 de enero de 1932. Larache. Caja (15)13.1.81/00703.

${ }_{44}$ AGA. Despacho de la Intervención regional del Sector de Tetuán dirigido a la IGITJ. 18 de mayo de 1932. Caja (15)13.1.81/00703.

${ }^{45}$ AGA. Carta de la Central de Larache dirigida a la IGITJ. 25 de febrero de 1931. Caja (15) 13.1.81/00664.
} 
mencionado. La escasa rentabilidad del santuario, que amenazaba con la emigración de algunos jerifes en busca de trabajo a otros pueblos de la zona, no servía a los intereses de la Intervención colonial, que apostaba por el mantenimiento del santuario como centro de uso político necesario para el funcionamiento del caciquismo marroquí tradicional dentro del sistema colonial.

En estas circunstancias, las autoridades españolas procuraron restringir el beneficio de las limosnas para preservar la función social del jerifismo marroquí. Por esta razón, examinaron los árboles de las genealogías jerifianas y su abolengo religioso, como demuestran los trabajos realizados sobre la rama de los Wulād al-Baqqāly las dudas que se formularon con respecto a su origen jerife. ${ }^{46}$

No obstante, el ejemplo más evidente de la protección colonial de la función social del jerifismo del monte Alam fueron las injerencias del Servicio de Intervención en la disputa entre los 'alamiyyīn y los raḥmūniyyīn sobre el reparto de las limosnas. El coronel Fernando Capaz había mandado una carta en 1930 al Gran visir Ibn 'Azūz, ${ }^{47}$ pidiéndole que resolviera el conflicto entre las dos ramas jerifianas, lo cual se consiguió a través de una confirmación oficial de los ulemas de que los raḥmūniyyīn eran hijos de SīdīMuḥammad b. 'Abd al-Salām b. Mašiš, un linaje refrendado por los dahíres de los sultanes de Marruecos; por lo tanto, sus derechos en el reparto de las limosnas quedaron intactos. ${ }^{48}$

Unos años más tarde, las autoridades coloniales volvieron a abrir el expediente, considerando que esta rama de raḥmūnyyīn no tenía derecho a estas limosnas en virtud de la decisión del nuevo Gran visir AḥmadGanmia, que no ratificó la opinión de su antecesor. En un Informe de la Inspección general de Tetuán enviado a la Central de Intervención regional de Gomara-Chauen se puede leer lo siguiente:

Sobre el reparto de las limosnas hechas al santuario de Muley Abdsalam entre los xorfa descendientes del santo, a este respecto y después de estudiar el asunto con todo detenimiento, debemos informarle de lo siguiente: que los Ulad el Axhab son yamlahiun y no pertenecen a los descendientes de Muley Abdsalam. Que los Ulad Rahmun tampoco son descendientes suyos, siendo tan sólo chorfayansiun. En consecuencia, no siendo ni los UladAxhab, ni los Ulad Rahmun descendientes de Mulay Abdsalam, no pueden invocar derecho alguno a ser partícipes de sus fetohas (limosnas). En cuanto a los Ulad ben Maseud, de YebelHabib, que alegan ser descendientes de los UladTribak, no hemos encontrado relación con Muley Abdsalam, pero, no obstante, si ellos tienen algún documento justificativo de su demanda, deberían presentarlo a fin de que, si ello es así, les sea conferido en forma legal. ${ }^{49}$

Las autoridades coloniales intentaron proteger la rentabilidad del santuario a través de la restricción del derecho a acceder a las limosnas para no romper la estructura social de los jerifes de YabalAlam, que controlaban un espacio religioso de gran importancia en la agenda política del protectorado español. Es decir: después de limitar el papel político de los jerifes en relación con el Estado, la autoridad colonial vuelve a destacar el liderazgo social jerifiano eligiendo a una élite dentro de la élite de los jerifes para que funcionara como una institución política intermediaria en lugares o circunstancias concretas, según los intereses del régimen colonial.

\footnotetext{
${ }^{46}$ AGA. Dahíres en árabe adjuntos a trabajos sobre los bakalen y su abolengo religioso. Caja (15) 13.1.81/00664.

${ }^{47}$ AGA. Carta del coronel Fernando Capaz enviada al Gran visir Ben Azuz. 24 de julio de 1930. Caja (15) 13.1.81/00664.

${ }^{48}$ AGA. Carta oficial del Gran Visir Sidi Mohamed ben Azuz enviada al coronel Capaz. 14 de octubre de 1930. Caja (15) 13.1.81/00664.

${ }^{49}$ AGA. Informe del Inspector General de la IGITJ enviado al Interventor regional de Gomara- chauen. 19 de enero de 1934. Tetuán. Caja 81/664.
} 


\section{El uso político del jerifismo durante los años de la estabilidad del régimen del protectorado (1939-1956)}

Coexisten en la antropología dos formas de análisis político, no contrapuestas entre sí, pero que usan términos analíticos muy diferentes a la hora de explicar la estructura del poder: la que se interesa en analizar al grupo humano y sus mecanismos sociales y la que pone más énfasis en la formación y la función de las simbologías usadas por las autoridades (González Alcantud 1988, 134). Para analizar el fenómeno del liderazgo sociopolítico en el régimen colonial español nos encontramos con un aspecto más cercano a la estructura social y a la reproducción política que a la simbología como práctica habitual del poder.

La aparición de un líder tiene que ver ante todo con la persistencia de la jerarquía y con la génesis del carisma. Bailey distinguió entre líderes clientelares y líderes morales, que en muchos casos pueden corresponderse con esos dos conceptos. Como explicó Dumont, se trata de una combinación de preeminencia parental, legitimidad religiosa y acción política (González Alcantud 1997). En el caso marroquí, Hassan Rachik comprobó la dualidad entre jerarquía y carisma en liderazgo político/religioso de los linajes jerifianos de Marruecos (Rachik 1992) Cuando el líder posee la legitimidad genealógica pero no tiene el consenso social, está derrotado políticamente y su liderazgo es víctima de luchas segmentarias. Eso fue lo que ocurrió históricamente con el liderazgo de Raysūnī.

\section{El jerifismo marroquí en el sistema del caciquismo político colonial}

La complejidad que otorga la fragmentación de las sociedades tribales convierte a los líderes de éstas en productos de varias estructuras, entre las que hay que subrayar el linaje, las jerarquías de edad, el honor y la posesión o usufructo de los recursos naturales. En estas circunstancias, el liderazgo es básicamente un vínculo clientelar que se establece entre el líder y sus seguidores (González Alcantud 1988,136).En este sentido, la instalación del régimen del protectorado no cambió nada en el tejido social marroquí. Las mismas familias poderosas de la época precolonial se mantuvieron en las altas esferas del Majzen español.

Durante la retirada española de Yebala en noviembre de 1924, ordenada por el dictador y alto comisario Primo de Rivera, el hijo de Wuld Sīdī al-Ḥasan, el primer cabecilla de la yihad contra los españoles, colaboró con los oficiales del ejército español, ayudando con su gente a evacuar las posiciones con poco control territorial. En realidad, fue Raysūnī quien negoció esta retirada con el capitán Interventor García Figueras a cambio de dinero y armas. Después de la derrota de este último, 'Abd al-Salām b. Muḥammad b. wuld Sīdī I-Ḥasan wuld Sayyid, apareció en la escena política como partidario del Majzen colonial, informando a los militares españoles durante la Guerra del Rif sobre la situación política de Beni Aros y señalando qué poblados debía bombardear la aviación española. Se trataba de una estrategia para mantener el poder tradicional de su familia en esta cabila (Mateo Dieste 2003, 418-419).Tras la pacificación definitiva del territorio, los españoles consolidaron a este prestigioso jerife, nombrando en 1928 a Sī 'Abd al-Salām caíd de Beni Aros y a su hermano al-Mufddal, jalifa del caíd. Los Wulād al-Ḥasan tomaron el control político de su cabila y aseguraron la continuación del sistema tradicional del caciquismo social, entre el poder central y sus clientes locales. En 1946, Sī 'Abd al-Salām fue presentado en la prensa española de Larache de este modo: 
"El Caíd de Beni Aarós, el prestigioso religioso Si AbdesalamUeldSidiLahsen, respetado y querido por los arosín debido a su prestigio religioso y a su aureola de hombre justiciero que interpreta fielmente las disposiciones del Majzen y de la nación protectora". ${ }^{50}$

No obstante, el ejemplo ideal para corroborar este análisis de la política colonial, que protegía la retransmisión del poder de los linajes jerifes de padre a hijo fue, sin duda alguna, el hijo del propio Raysūnī, Muḥammad Jālid Raysūnī. Éste ocupó el puesto de bajá de Larache, la segunda ciudad más importante del Marruecos español. Se trata de una figura que merece mucha atención, no sólo por su papel político en la época de la estabilidad del protectorado español, sino también por su legado político y cultural. Durante décadas, la memoria popular en Larache recordaba al bajá como un gobernador fuerte, sabio y duro; una especie de tirano justo, un imaginario tradicional propio del patrimonio político del Islam. Jālid Raysūnī fue un personaje clave en la red del clientelismo social español en su zona de influencia, y el principal actor político en nombre de los jerifes de Yebala. Su obra política fue incluso más importante que la del jalifa Mūlāy al-Ḥasan b. alMahdī, puesto que el bajá de Larache disponía de autoridad e influencia efectivas en la región de Lucus y su capital, Larache. Ejercía un control absoluto sobre las cabilas y gozaba de una absoluta confianza por parte de la autoridad española. En las excepcionales circunstancias de la independencia de Marruecos, fue objeto de persecución por parte de los nacionalistas marroquíes, que incendiaron su casa de Larache y mataron a varios de sus sirvientes, obligándole a refugiarse en España acompañado de su familia en 1956. La revuelta popular que terminó con su exilio sigue siendo uno de los enigmas de la historia contemporánea de Marruecos y que genera numerosas preguntas hasta hoy en día. ${ }^{51}$ En las siguientes páginas intentaré arrojar nueva luz sobre este asunto, que sirve como modelo para entender el uso político del jerifismo marroquí en esta etapa del colonialismo español.

El bajá de Larachenació en Tazarut en enero de 1909. Era el primogénito del jerife Mūlāy Aḥmad Raysūnī, sultán de Yebala, con quien vivió en sus primeros años y compartió las vicisitudes de esta época de inestabilidad política en la zona española. Fue hecho prisionero junto a su padre por el príncipe del Rif Muhammad b. 'Abd al-Karīm y fueron llevados a Tamasnit (Beni Urriaguel). A la muerte de su padre fue puesto en libertad en Chauen, desde donde se trasladó a Tetuán. En la capital del Protectorado, su vida fue ordenada y se dedicó a los estudios, conviviendo en un ambiente español, pues se hallaba apartado de la sociedad musulmana. Incluso muchos se negaban a saludarle, pues pensaban que su padre era un asesino y un ladrón. En 1934, fue elegido por el general Fernando Capaz para ocupar el cargo de gobernador de la ciudad de Larache, actuando a satisfacción y en completo acuerdo con la Intervención Territorial de la región de Lucus. $^{52}$

Nombrar al primogénito del jerife Raysūnī bajá de la ciudad más rica del protectorado español no fue fruto de la casualidad, sino que fue un plan político para controlar el territorio del Lucus a través de un liderazgo social efectivo. A pesar del triste final de su patriarca en 1925, este clan jerife se mantuvo activo en política, intentando por todos los medios recuperar su poder tradicional en la zona. Jālid Raysūnī fue la persona más indicada para esta política española. A nivel cultural, dominaba los dos idiomas del régimen, el español y el árabe, de forma espléndida. El bajá de Larache era un intelectual de su época que llegó a publicar libros y a participar en la vida

\footnotetext{
${ }^{50}$ BNE.El Avisador de Larache, marzo de 1946, número extraordinario.

${ }^{51}$ Según el expediente personal de Sīdī Muhammad Jālid Raysūnī, bajá de Larache, en virtud de los dahíres de 20 de julio de 1957 publicado en el Boletín Oficial de la Zona Norte del Reino de Marruecos, el gobierno marroquí embargó todas sus propiedades. La policía marroquí detuvo el 19 de enero de 1959 a un escribiente marroquí de la Delegación de Cultura por mantener correspondencia con Raysūnī. Por todas estas circunstancias, el ex bajá de Larache se presentaría ante las autoridades españolas solicitando ser recibido por el Ministro Subsecretario de la Presidencia del Gobierno español. AGA. Expediente personal de Sidi Mohamed Jaled Ben Ahmed Raisuni.Caja (15) 57.81/12181.

52 AGA. Ficha de Sid. Mohamed Jaled Raisuní, ex bajá de Larache. 4 de diciembre de 1956. Tetuán. Caja (15) $57.81 / 12181$.
} 
cultural del Marruecos español. A nivel social, estaba casado con una mujer española viuda de un médico militar del ejército de África. Así pues, el jerife marroquí supuso la renovación de la presencia española en Marruecos. Apoyado por su clan jerife y los cuantiosos bienes heredados de su padre, ${ }^{53}$ Raysūnī restauró de nuevo la reputación de su familia mediante una sabia política de donativos y favores, según las fuentes españolas. ${ }^{54}$

Como ocurrió en Beni Aros con la facción de Wulād Sīdī al-Ḥasan, en Larache también los Wulād Raysūnī acapararon por completo durante más de veinte años el liderazgo sociopolítico en la ciudad y las cabilas de su territorio. El cargo de jalifa recayó sobre la figura de Muhammad b. Muḥammad Raysūnī, "un jerife fiel y cumplidor de las leyes coránicas", según la prensa española de la ciudad. El secretario del bajá Muhammad 'Alī Raysūnī, presidió la Asociación Benéfica Musulmana, una de las principales fundaciones de la caridad social de Larache española. ${ }^{55}$ Este clan político de los Raysūnī estaba vinculado a todos los niveles con el sistema de la Intervención colonial, que ejercía el poder político real a través de esta red de gobierno indirecto. El hermano de Jālid Raysūnī, Sīdī Muḥammad Hašim Raysūnī, contrajo matrimonio en 1945 con Sarita Mizzian Amor, una de las hijas del poderoso general marroquí del ejército español Mohamed ben Mizzian, que ocupaba entonces el puesto de jefe Interventor del Territorio de Larache. ${ }^{56}$ Según estos datos, el régimen colonial español no cambió en nada la estructura de la denominada "buena sociedad musulmana"; los mismos linajes jerifes de Yebala se mantuvieron en el poder junto a los notables tribales del Rif. La endogamia como práctica social de carácter político seguía en vigor como principal reproductor de la élite social, con las mismas estipulaciones de la cultura marroquí tradicional. En este contexto, el capital social comienza con la simbología religiosa del origen jerifiano y termina con el monopolio de los recursos económicos y la acumulación de riqueza.

Este carácter poderoso del origen jerifiano, se blindaba aún más en el sistema político colonial durante la Guerra Civil española. Las autoridades coloniales trasladaron a España el sistema de la intervención creado en el protectorado para gestionar los asuntos indígenas de los marroquíes que formaron la columna vertebral del Ejército de África. En este contexto se encuadra el viaje realizado por el bajá de Larache Jālid Raysūnī a varias ciudades españolas, organizado por el responsable del Servicio de la Intervención en la península, el coronel Juan Sánchez Pol. ${ }^{57}$ La visita del bajá marroquí a Santander, que tuvo lugar el 19 de octubre de 1937, al-Raysūnī, como letrado y jerife usaba su poder moral para animar a los heridos de guerra que se encontraban en el hospital de Santander, y también aprovechó la ocasión para distribuir donativos. ${ }^{58}$ Un cúmulo del capital simbólico jerifiano, que junto al económico, resultó útil para que las autoridades mantuvieran la lealtad de las tropas moras en una guerra difícil de justificar por el sacrificio masivo de vidas marroquíes. ${ }^{59}$

\footnotetext{
${ }^{53}$ A pesar de las reclamaciones jurídicas contra el jerife AhmmadRaysūnī por adquirir propiedades utilizando la violencia y el saqueo, las autoridades coloniales otorgaron muchas de estas propiedades a sus herederos directos, como en el caso de un terreno de YabalHabib, donde los españoles aceptaron el nombramiento de un representante elegido por el hijo de este JālidRaysūnī. AGA. Cartas sobre la gestión de los bienes de Raisuní. Caja (15)013. 81/00723.

54 AGA. Ficha de Sid Mohamed Jaled Raisuní ex bajá de Larache. 4 de diciembre de 1956. Tetuán. Caja (15) $57.81 / 12181$.

${ }^{55}$ BNE. El Avisador de Larache, 30 de abril de 1944.

${ }^{56}$ BNE. El Avisador de Larache, marzo de 1946, número extraordinario.

${ }^{57}$ BNE. Para la labor del coronel Sánchez Pol en este servicio colonial, véase: J. Sánchez Pol. Servicio de Intervenciones marroquíes en España, memoria de 1936-1939. Texto mecanográfico.

${ }^{58}$ AGA. Falange Española. 19 de octubre de 1937. Caja (15)13.01. 81/01186.

59 El bajá de Larache fue acompañado por un séquito de diez caídes que participaron en su recorrido entre las ciudades de Santander, Salamanca, Bilbao, Valladolid y San Sebastián. Visitaron incluso el frente del cinturón de REIM No 28 (junio 2020)

ISSN: $1887-4460$
} 
Por lo tanto no era extraño el contenido de la carta elevada al Alto Comisario Luís Orgaz Yoldi (1936-1937), por el clan de los raysūnī en estas fichas de la contienda española, los jerifes raysūniyīn adoptaron la misma terminología colonial, abogando por la obra civilizadora de España en Marruecos, reconociendo los esfuerzos de la Junta Rural en la construcción de un lavadero para mujeres, fuentes y pozos en Tazarut, a pesar del presupuesto limitado de la localidad, y destacando fuertemente el prestigio jerife de su poblado, considerado por los marroquíes en sus "distintas razas" como el polo espiritual de las cabilas del monte, y como reposo y descanso en el camino de la peregrinación a Mūlāy 'Abd al-Salām. Por ello, los jerifes pedían la construcción de retretes en la mezquita y la madraza, así como una residencia para los estudiantes que acudían al poblado a cursar estudios coránicos según la antiquísima tradición islámica. ${ }^{60}$ La carta llevaba adjuntos treinta y dos extractos de dahíres de los sultanes de Marruecos que otorgaban a esta rama jerife mayores respetos y consideraciones. Los originales estaban en posesión del bajá de Larache, JālidRaysūnī, ${ }^{61}$ que usaba esta categoría social como capital simbólico para negociar con las autoridades españolas la recuperación del rol religioso de su poblado natal y volver a situarlo en el mapa político del régimen colonial.

Es evidente que Jālid Raysūnī tuvo éxito en este sentido, como demuestran detalladamente las fuentes españolas, expandiendo la red de intereses económicos que construyó junto a su familia en Larache, dedicándose a los negocios a gran escala y efectuando importantes operaciones de importación, gracias al trato especial por parte de los españoles, que promocionaron su actividad comercial. La Delegación de la Economía del protectorado llegó a escribir en 1946 una carta a la Dirección General de Marruecos y Colonias en Madrid para facilitar la exportación de Málaga a Marruecos de 250 cabras. El escrito oficial abogaba por una intervención directa de la Subsecretaria de la Presidencia del Gobierno español para allanar las dificultades jurídicas que imponía el Gobierno Civil de la ciudad española, ${ }^{62}$ lo que se consiguió a través de un telegrama dirigido al Gobernador Civil de Málaga, autorizando la agilización de la actividad económica de Raysūnī por "el alto cargo que despeña en la administración majzeniana de nuestro protectorado marroquí". 63

El bajá de Larache llegó a montar una entidad comercial llamada Trébol que fue creada en Madrid en 1944 por su familiar y secretario personal, Muhammad b. 'Alī Raysūnī, que solicitó la residencia permanente en España para hacerse cargo de la empresa. ${ }^{64}$ También realizó junto al bajá importaciones de cartuchos de caza y mercancías de seda con valor de seis millones de pesetas, desde Francia a Marruecos a través de Barcelona. ${ }^{65}$ En 1951, la fortuna del jerife larachen se llegó

\footnotetext{
hierro, construido por los "rojos" en sus intentos de defender Madrid. En Valladolid fue acompañado por el coronel Sánchez Pol. El bajá declaró a la prensa de la ciudad, hablando del "elevado espíritu patriótico que reina en la nueva España del Generalísimo Franco, donde no sólo el orden es absoluto, sino también el envolvimiento de la vida que se hace con entera y absoluta normalidad". AGA. Diario regional de Valladolid. 2 de noviembre de 1937, y otros recortes de prensa. Caja (15) 13.1. 81/01186.

${ }^{60}$ AGA. Carta de los jerifes raisuniyyin elevada al Alto Comisario de España en Marruecos Luís Orgaz Yolidi. S.f. Caja (15) 31.1.81/1902.

${ }^{61}$ AGA. Extractos de los dahíres jerifianos traducidos al castellano, referentes a los señores Raysūnī desde 1599, entre ellos un dahír de MūlāySulaymān (1792-1822):A nuestro querido y bendito hermano Muley el Taieb. Y después: debéis saber que nuestro hermano en Dios, el virtuoso y generoso Sidi Ali Ben Raisun, estuvo en una reunión de chorfa suyos (...) esperamos reconozcáis la estima en que tenemos y el aprecio que le merecemos nosotros, y los atendáis tanto a ellos como a los demás chorfa, considerándolos y respetándolos y deis además igual trato a todos los que a ellos se allegan, amistades y subordinados, por ser estos chorfa muy merecedores de ello (...). Caja (15) 31.1.81/1902.

${ }^{62}$ AGA. Carta del Delegado de Economía de la Alta Comisaría de España en Marruecos dirigida a la Dirección General de Marruecos y Colonias. 27 de septiembre de 1946. Caja (15)57.81/12181.

${ }^{63}$ AGA. Telegrama del Director General de Marruecos y Colonias dirigida al Gobernador civil de Málaga. Caja (15) $57.81 / 12181$.

${ }^{64}$ AGA. Minuta del Director General de Marruecos y Colonias. 9 de marzo de 1944. Madrid. (15) 57. 81/12181.

${ }^{65}$ AGA. Informe sobre actividades de notables musulmanes de la Dirección General de Marruecos y Colonias dirigido al secretario de la Alta Comisaría.11 de mayo de 1944. Madrid. (15) 57. 81/12181.
} 
a valorarse en treinta y nueve millones seiscientas mil pesetas en bienes diversos. ${ }^{66}$ Esta relación clientelar con España existía a cambio de un compromiso total con su obra política en Marruecos. En un prólogo redactado por el propio Jālid Raysūnī en el libro de García Jaén De España y del Islam, el jerife marroquí defiende fuertemente la doctrina colonial de la hermandad hispanomarroquí de este modo:

"(...) España, con una fraternal generosidad que emociona hasta al más escéptico, nos cuenta las gloriosas conquistas intelectuales de nuestros antepasados, abriendo así cauces de estímulo al estudio, para que nuestra descendencia ponga sus aspiraciones en aquel esplendor" (García Jaén 1954).

En esta etapa de la historia del protectorado español, el uso político del jerifismo marroquí llegó a su auge con el surgimiento del movimiento nacionalista. Las autoridades coloniales necesitaban un contrapeso político para hacer frente a las reivindicaciones reformistas. En este contexto, hallaron en la figura de Jālid Raysūnī, patriarca del clan jerife más importante del norte de Marruecos, un componente fundamental para actuar políticamente en un terreno social marcado por un fuerte tradicionalismo. La confianza en Raysūnī fue absoluta: le dieron libertad total para contrarrestar la propaganda nacionalista con la fundación del Partido Liberal (al-Ahrār), oponiéndolo al partido nacionalista de Abdeljalaq Torres. En realidad, la estrategia de la Alta Comisaría consistía desde el mandato del coronel Beigbeder (1937-1939) en tolerar una pluralidad política controlada para evitar la agrupación de la élite marroquí en el partido de Reforma Nacional. ${ }^{67}$

Las autoridades españolas llegaron a plantearse reforzar el prestigio social de los jerifes 'alamiyyīn - de YabalAlam, la rama jerife principal a la que pertenecían los Wulād Raysūnī - otorgándoles por dahír una parte esencial de la dirección de los actos religiosos de la nsja(Gregori 1939), ${ }^{68} \mathrm{el}$ ritual más prestigioso del Santuario jerife de Yebala.

Como es costumbre en Marruecos, las principales batallas políticas tenían lugar en la esfera religiosa. En 1934, los nacionalistas criticaron duramente en el periódico al-hayāt la dirección que había seguido la Asociación Benéfica Musulmana de la ciudad de Larache, acusando su director, al'Asrī, un notable cercano al bajá de la ciudad, de convertir la asociación pública en una propiedad privada al servicio de su familia. Más tarde, Raysūnī escribió a las autoridades españolas con respecto a este asunto:

En el momento actual, el Magreb no necesita política de ninguna clase, sino estudio y cultura en todos sus aspectos. Los periódicos (nacionalistas) están llenos de cuentos y chismes de redacción, unos contra otros, falsedades contra caídes, cadíes, interventores...etc., que sólo son envidias y deseos de derribar a unos para colocar a otros; todo esto lleva a la perturbación al pueblo en general, que ve en los periódicos cómo se culpa a las autoridades y los ignorantes lo creen, llegando un día en que resultará esto perjudicial.(Gregori 1939).

En 1946, en la 'māra(romería) del santuario de Sīdī Mezuar, en la Cabila de Sumata, a la que asistieron miles de peregrinos de las tribus de Yebala, el bajá de Larache realizó propaganda

\footnotetext{
66 AGA. Ficha de Sid Mohamed Jaled Raisuní, ex bajá de Larache. 4 de diciembre de 1956. Tetuán. Caja (15) $57.81 / 12181$.

${ }^{67}$ El partido de la Unidad Nacional, liderado por al-Makkī Nāșirī, fue también fundado por indicaciones de la Alta Comisaría. Por otro lado, el Partido liberal tuvo otro líder en el Rif, Būdrā al-Jattābī, sobrino de 'Abd al-Karīm. (Gregori 1939).

${ }^{68}$ Lansaja es la romería de Mulay 'Abd al-Salām b. Mašiš celebrada anualmente en el 15 de ša'bān.
}

REIM No 28 (junio 2020)

ISSN: $1887-4460$ 
política en contra de la dinastía alauí y su permanencia en el trono, y a favor de la rama idrisí, a cuyo linaje pertenecían los Wulād Raysūnī. ${ }^{69}$ Aunque las fuentes orales marroquíes se limitan a decir que Raysūnī solamente pretendía ocupar el puesto del jalifa para hacer realidad el sueño de su padre, pensamos que la narrativa española es más acertada, teniendo en cuenta que la monarquía sigue siendo en Marruecos un tabú del que no se debe hablar. ${ }^{70}$ No sabemos a ciencia cierta si la naturaleza de esta campaña contra la dinastía alauí fue simplemente una actuación individual de Raysūnī o si se trató de un plan político de la Alta Comisaría para entablar una pugna de alto nivel entre las ramas jalifianas del sultanato marroquí.

En realidad, no tenemos respuesta a esta cuestión, pero no parece probable que esta actitud del bajá de Larache hubiera sido posible sin el prestigio que le confería su alto rango en el protectorado español en el que había llegado a disponer de importante influencia desempeñando un papel político esencial en el régimen colonial. Como consecuencia de ello, las relaciones con la casa jalifiana tornaron a peor. El jalifa se negó a recibirle en años sucesivos durante la pascua del mawlid (el nacimiento del profeta muhammad), como era tradición con las autoridades regionales de la zona. Sin embargo, su posición política se mantenía intacta. Durante los incidentes nacionalistas del mes de Ramadán de 1946, Jālid Raysūnī publicó un manifiesto titulado "La voz de los hombres de la zona Jalifiana", un documento político aprobado "de puño y letra" por el alto comisario, que pretendía lanzar una propaganda musulmana de carácter conservador para contener la ofensiva nacionalista. ${ }^{71}$ Este manifiesto condenaba duramente las reivindicaciones nacionalistas, vinculándolas al anarquismo político, anarquismo que debía ser extirpado del seno de la sociedad marroquí, que para Raysūnī todavía necesitaba la tutela española. En Tetuán se organizó un acto en el que el nā'ib (delegado) del Gran visir leyó un discurso de apoyo político a Raysūnī y a su postura de seguir por el camino de la colaboración con España. ${ }^{72}$

Aunque trató de sacar partido a la instrumentalización por parte del protectorado español de las figuras autóctonas del poder moral en la estructura social de la región de Yebala, Raysūnī era consciente de los riesgos que implicaba esa posición política. Por ello a partir de principios de los años cincuenta, pidió oficialmente la protección norteamericana a través del Ministerio de Estados Unidos en Tánger, tomó la iniciativa para hacer las paces con la casa jalifiana de Tetuán en 1954, y mantuvo una relación política con el líder nacionalista Muḥammad Ḥasan al-Wazānī, poniendo una propiedad suya en Tánger al servicio del partido Šūrāwa l-Istiqlāl, encabezado por éste. ${ }^{73}$

Pero parece que todo esto no fue suficiente para integrarse en el Majzen postcolonial, como ocurrió con la mayoría de los altos cargos del protectorado en Marruecos, tanto en la zona francesa como la española. El 17 de abril de 1956, Raysūnī se dirigió al zoco de Telat de Risana acompañado por cuatro soldados y de su cuñado, Mūlāy Aḥmad, con el objetivo de clausurar el local del partido nacionalista al-Istiqlāl en dicho poblado. El intento se convirtió a una revuelta popular que se extendió rápidamente por la ciudad de Larache, donde asaltaron su palacio y mataron a sus sirvientes. Raysūnī se refugió en Ceuta y más tarde se trasladó a Málaga, ${ }^{74}$

\footnotetext{
69 AGA. Ficha de Sid. Mohamed Jaled Raisune ex Baja de Larache. 4 de diciembre de 1956. Tetuán. Caja (15) $57.81 / 12181$.

70 Las entrevistas orales mantenidas con ancianos de la ciudad de Larache así lo reflejan recordando este acontecimiento de maneras diferentes y mencionando lugares y fechas distintas. Algunos no se atrevieron a mencionar la monarquía, pero aludieron a que ocurrió algo grave; otros creían que solamente se trataba de que Raysūnī, como su padre, pretendía ocupar el puesto del jalifa de la zona española. julio de 2016.

71 AGA. Ficha de Sid. Mohamed Jaled Raisune, ex bajá de Larache. 4 de diciembre de 1956. Tetuán. Caja (15) $57.81 / 12181$.

${ }^{72}$ AGA. Informe sobre el nacionalismo marroquí de la Sección Política de La DAI. Redactado por el Capitán Fernando Frade. Caja (15) 000. 81/12694.

${ }^{73}$ AGA. Ficha de Sid. Mohamed JaledRaisune ex bajá de Larache. 4 de diciembre de 1956 . Tetuán. Caja (15) 57. 81/12181.

${ }^{74}$ lbíd.
} 
poniendo fin a un capítulo de la historia de la Larache española que permanece grabado aún hoy en día en el imaginario popular de la ciudad de Lucus. ${ }^{75}$

\section{El jerifismo como recurso en la política exterior española hacia el mundo árabe}

En la etapa final del protectorado en Marruecos, España estaba en una situación de aislamiento diplomático, aunque contaba con el apoyo de los países árabes para su ingreso a la ONU. ${ }^{76}$ La crisis del trono marroquí de 1953, tras el exilio del Sultán Muḥammad V, permitió a la España franquista reforzar la imagen que había proyectado años atrás con su política pro-arábiga como garante de la legitimidad político-religiosa del sultanato de Marruecos y como defensora de las instituciones islámicas en el ámbito internacional (Velasco de Castro 2002, 149). Esta crisis había sido un auténtico golpe de Estado contra la legalidad política y religiosa del Sultán marroquí. Los franceses contravenían gravemente el tratado de Fez de 1912, al haber sido destronado el Sultán de Marruecos que se habían comprometido a proteger. Desde la óptica marroquí, Muhammad $V$ no representaba solamente al poder político como máxima autoridad del gobierno majzení, sino que cobraba mucha más importancia el hecho de que fuera el Sultán jerife en Marruecos.

Desde fechas tempranas del movimiento reformista en la zona jalifiana, los nacionalistas marroquíes descendientes de notables andalusíes integrados desde hace generaciones al servicio del Majzen marroquí, ${ }^{77}$ sabían cómo manejar esta simbología jerifiana en beneficio de su causa. Durante la famosa visita de Muhammad V a Tánger en 1947, el partido nacionalista organizó un acto de hadiyya al sultán en nombre de la población norteña. El regalo consistía en una placa con una representación grafica de Marruecos en oro, donde aparecían resaltadas las capitales históricas del país: Fez, Marrakech, Tetuán y Rabat. Este mapa sin fronteras coloniales señalaba con adornos artísticos el mausoleo del santuario de Mūlāy'Abd al-Salām. El líder del partido nacionalista AbdeljalaqTorresse dirigió este día 2 de abril en la Mezquita Grande de Tánger al Sultán Muhammad V con estas palabras: "Nuestro señor Imán, os ruego aceptéis esta hadiyya como prueba de nuestra sumisión a vuestro trono y vuestra gloriosa dinastía alauita";conectando de esta forma la legitimidad jerifiana de la dinastía contemporánea del país con el origen histórico del linaje jerife que encarna el santuario de Yebala como emblema de la dinastía idrisí, la primera en la historia de Marruecos. ${ }^{78} \mathrm{Un}$ discurso de nacionalismo religioso (salafaiyya wațaniyya) profundamente anticolonial y de gran impacto político en la sociedad del Protectorado.

\footnotetext{
${ }^{75}$ AGA. Nota S.f. adjuntada al expediente personal de Sidi Mohamed Jaled Ben Ahmed Raisuni: "el bajá de Larache ha solicitado la nacionalidad española con el fin de residir en España donde montará negocios, creando una sociedad inmobiliaria a la que ha aportado su capital de Marruecos. Se hicieron gestiones cerca del Director General de Seguros para que se le abonaran más de un millón de pesetas, importe de los daños causados en Larache". Caja (15) 57. $81 / 12181$.

${ }^{76}$ En la prensa árabe de Tetuán se publicó una declaración del ministro del Líbano en España, en la que insistía en que todos los países árabes habían realizado las gestiones necesarias para pedir el ingreso de España en la ONU y eliminar el tratado internacional de diciembre de 1946, en virtud del cual se efectuó la retirada de los embajadores extranjeros de Madrid. El responsable libanés dijo que ya estaba decidida la reivindicación colectiva por parte de los países árabes para que volvieran las misiones diplomáticas extranjeras a España, y se refirió a la importancia de apoyar políticamente, junto con los países de América Latina, la solicitud oficial de Brasil respecto al ingreso de España en las Naciones Unidas. BNE. "Los árabes apoyan a España". Al-chihab, 22 de mayo de 1949.

77“(...) toda la juventud musulmana de las familias más notables se ha afiliado a este partido (PRN), que ya no cree en los milagros de los santos. La idea religiosa se ha mezclado con de la Independencia de Marruecos (...)". AGA. Informe de notas sobre el uahabismo y salafismo de Marruecos. DAI. 12 de abril de 1930. Caja (15) 57.81/12699.

${ }^{78}$ AGA. Informe sobre nacionalismo marroquí del primer trimestre de 1947. Sección Política de la DAl. Caja (15) $57.81 / 12694$.
} 
En la década de los 50,la figura de Muḥammad $V$ se convirtió en un signo nacional de carácter religioso. Los nacionalistas marroquíes, a pesar de su apego por la purificación religiosa, le atribuyeron grandes poderes sobrenaturales, como la aparición de su rostro en la luna. ${ }^{79}$ Fue una táctica política y religiosa propia de la tradición sufí en Marruecos utilizada para movilizar a las masas en favor de la causa independentista. El elemento jerife fue necesario para que tuviera éxito, pero no fue el único factor determinante.

En estos años de pugna contra el colonialismo francés, los nacionalistas marroquíes y las autoridades españolas se unieron en sus denuncias. Entre la documentación española, encontramos un escrito de una protesta colectiva de jueces, jerifes y notables del protectorado español elevado al Generalísimo Franco, "que ha sabido recoger por su política en Marruecos los sentimientos más hondos del pueblo marroquí". Los líderes marroquíes no reconocían la legitimidad de Ibn 'Arafa, el Sultán impuesto por los franceses, y pedían la ruptura completa con la zona francesa bajo la autoridad del jalifa Mūlāy al-Ḥasan b. al-Mahdī, rindiendo homenaje a España y su Caudillo. ${ }^{80}$

En realidad, la zona española se transformó prácticamente en un bastión de rebeldía antifrancesa. Incluso los españoles llegaron a suspender el plan de transformar su zona de influencia en un sultanato independiente, con el jalifa al frente, con la misma legalidad política y religiosa del Sultán de Marruecos, según el acuerdo hispano-jalifiano de 1950. No obstante, el ritmo y el cariz que estaban tomando los acontecimientos dejaban claro que Muhammad $\mathrm{V}$ era insustituible, ni por el jalifa de la zona española, ni por el Sultán de los franceses (Velasco de Castro 2002, 153). Los tres personajes eran miembros de la misma familia jerife, pero solamente el primero adquirió, bajo determinadas circunstancias históricas, la representación nacional colectiva que el jerifismo marroquí resucitaba a menudo en épocas de crisis (El Ghazi El Imlahi 2020, 77-113).

La decisión española de apoyar la legitimidad del trono marroquí hizo que la Alta Comisaria de España en Marruecos llegara a acceder a la presencia militar de elementos nacionalistas en las montañas del Rif, desde donde el Ejército de Liberación Marroquí lanzó ataques hacia la zona francesa (Hernando de Larramendi 2017). Esta estrategia se enmarcaba en la agenda internacional hacia el mundo árabe de la España franquista (Hernando de Larramendi, González y López 2015). Aunque con respecto a la protección del statu quo en el Protectorado, dicha estrategia no tuvo lógica política alguna, puesto que cualquier desequilibrio de poder en la zona francesa repercutiría irremediablemente el norte español. Las autoridades españolas se ofuscaron en oponerse a Francia, que era la bestia negra de Franco, sin disponer de una perspectiva política a largo plazo sobre el futuro de su empresa colonial. Aunque, por otro lado, España estaba resolviendo a través del jerifismo marroquí el gran desafío del primer franquismo: el ostracismo político.

En este contexto de búsqueda de apoyos dentro del bloque árabe para salir del aislamiento internacional (Hernando de Larramendi 2016), España aprovechó el incidente de la violación del santuario de Mūlāy Idrīs, el padre espiritual del jerifismo en Marruecos, por parte de las fuerzas negras del Sultán Ibn 'Arafa en 1954, considerado por los ulemas un suceso de doble profanación. ${ }^{81}$ Se movilizó por ello a las masas musulmanas en lecturas masivas del lațîf llamamiento religioso en tiempos de crisis - en las mezquitas, como acto de desagravio para denunciar esta máxima ofensa francesa contra el Islam marroquí. ${ }^{82}$ La Alta Comisaría, aconsejada por ulemas de su propia administración colonial, reunió una comisión de treinta jerifes de entre

\footnotetext{
${ }^{79}$ Es una anécdota histórica frecuente en Marruecos hasta el día de hoy, un mito fundador del nacionalismo en este país (Muhammad al-Rāyī 2013).

${ }^{80}$ AGA. Libro de firmas titulado Marruecos a España. Caja (15) 57. 81/12709.

${ }^{81}$ AGA. Carta de Hach Mohamed B. SidiHach Baraca, el presidente del Tribunal Superior de la Aplicación de la Chariaa dirigida al delegado de Asuntos Indígenas Tomás García Figueras. 21 de agosto de 1954. Tetuán. Caja (15) 31.1.81/01902.

${ }^{82}$ AGA. Nota informativa de la Sección Política elevada al delegado de asunto indignas. Caja (15) 31.1.81/01902.
} 
cincuenta y sesenta años de edad - el prestigio de la edad es importante en la cultura árabe - para realizar un acto de protesta oficial en la propia sede de la Alta Comisaría. Tras la entrevista con el alto comisario, la comisión de los jerifes se presentó en el Palacio jalifiano para denunciar la actitud francesa. ${ }^{83}$ Los españoles pretendían dar a estos actos propagandísticos la mayor resonancia posible entre los musulmanes, especialmente en Oriente Medio.

El uso del jerifismo como recurso político fue útil para servir a los intereses de España, incluso en la esfera internacional. Sin embargo, como mostró Velasco de Castro, finalmente esta gestión de la crisis del trono alauí fue una oportunidad perdida debido al inmovilismo español tras la vuelta de Muḥammad $V$ al trono en noviembre de 1955. España no supo beneficiarse a tiempo del retorno del Sultán al que apoyó en su exilio, y se quedó atrapada en su ideal ficticio de la hermandad con el moro, hasta que se vio obligada a renunciar a su sueño africano después del acuerdo francomarroquí del 2 de marzo de 1956, que anexionó Marruecos entero a la dependencia cultural, política y económica de Francia que persiste hasta la actualidad (Velasco de Castro 2002, 155-162).

\section{Conclusiones}

Para los sectores conservadores de la empresa colonial española, el jerifismo fue un modo de liderazgo social más útil y compatible con la agenda política del protectorado que el sufismo de las cofradías que conformaba en el imaginario colonial un elemento de poder religioso más confuso. La analogía entre los jerifes marroquíes y los señores feudales de la edad media europea facilitó la comprensión y el trato con este componente social marroquí más fácil de entender para los responsables de la administración colonial.

Aun así, en los primeros años del Protectorado, los españoles cometieron grandes errores en la gestión política del jerifismo como estructura de liderazgo social, lo que provocó serios obstáculos en la instalación de las instituciones del nuevo régimen, sobre todo en Yebala, la cuna del jerifismo del norte marroquí.

Una vez alcanzado el control definitivo del territorio en 1927, las autoridades españolas tomaron la iniciativa para poner en marcha un plan de gestión social del jerifismo que terminó con su integración total en el sistema político del Protectorado. La reconstrucción de la red tradicional del caciquismo social en el marco del nuevo Majzen colonial facilitó finalmente el uso político de este recurso de poder por parte del protectorado español, tanto a nivel interior como en la esfera internacional. Sin embargo, el carácter limitado y conservador de la empresa colonial española condenó finalmente la obra cultural de España en su protectorado marroquí a una liquidación definitiva a favor de la influencia francesa en la época poscolonial.

\footnotetext{
${ }^{83}$ AGA. Nota informativa de la Sección Política de la DAl dirigida al alto comisario. 2 de septiembre de 1954. Tetuán. Caja (15) 31.1.81/01902.
}

REIM № 28 (junio 2020)

ISSN: $1887-4460$ 


\section{Archivos}

Archivo General de la Administración, Sección África.

Biblioteca Nacional de España: Colección García Figueras, Sección África.

\section{Referencias}

BURKE, Peter (1996): Venecia y Ámsterdam, estudio sobre las élites del siglo XVII, Barcelona, Gedisa.

DAY, W. Stephen (2012): Regionalism and Rebellion in Yemen: A Troubled National Union, Cambridge, Cambridge University Press.

EL GHAZI EL IMLAHI, Said (2020): La política religiosa del Protectorado español en el Norte de Marruecos (1912-1956), Tesis doctoral, Granada, Universidad de Granada.

FORBES, Rosita (2010): El Raisuni,sultán de las montañas. Córdoba, Almuzara.

GARCÍA FIGUERAS, Tomás (1939): Notas sobre el Islam en Marruecos, Larache, Centro de Estudios Marroquíes.

GARCÍA FIGUERAS, Tomás (1955): Marruecos, la acción de España en el Norte de África. Tetuán, Editora marroquí.

GARCÍA JAÉN, Antonio (1954): De España y del Islam, Tetuán, Editora marroquí.

GIL TORRES, Rodolfo (1923 a): "Los señores feudales en los dos Protectorados de Marruecos", Revista Hispano Africana, abril.

---- (1923 b) "Los señores feudales en los dos Protectorados de Marruecos II". Revista Hispano Africana, mayo.

GONZÁLEZ ALCANTUD, José Antonio (1988): Antropología (y) Política, sobre la formación cultural del poder, Barcelona, Anthropos Editorial.

GONZÁLEZ ALCANTUD, José Antonio (1997): El clientelismo Político, perspectiva socioantropológica, Barcelona, Anthropos Editorial.

GREGORI, Gonzalo (1939): El Movimiento Nacionalista marroquí en la región occidental. Larache, Delegación de Asuntos Indígenas.

HAMMOUDI, Abdellah (2007): Maestro y discípulo. Fundamentos culturales del autoritarismo en las sociedades árabes (trad. Patrick Lévy), Barcelona, Anthropos Editorial.

HART, David Montgomery (1997): Estructuras tribales precoloniales en Marruecos bereber, 18601933: una reconstrucción etnográfica en la perspectiva histórica, Granada, Universidad de Granada.

HART, David Montgomery (2006): Bandidismo en el Islam, estudios de casos en Marruecos, Argelia y la frontera norte de Pakistán, Barcelona, Anthropos Editorial.

HERNANDO DE LARRAMENDI, Miguel; GONZÁLEZ GONZÁLEZ, Irene y LÓPEZ GARCíA, Bernabé (eds.) (2015): El Instituto Hispano-árabe de Cultura. Orígenes y evolución de la diplomacia pública hacia el mundo árabe, Madrid, AECID. http://bibliotecadigital.aecid.es/bibliodig/i18n/consulta/registro.cmd?id=4461 [consulta: 20/4/2020]

HERNANDO DE LARRAMENDI, Miguel (2016): “España y el Mediterráneo: entre las inercias de la política pro-árabe y los avatares de una descolonización por etapas (1953-1986)" en Lorenzo Delgado Gómez-Escalonilla, Ricardo Martín de la Guardia y Rosa Pardo Sanz (eds.): La apertura 
internacional de España. Entre el franquismo y la democracia, 1953-1986, Madrid, Silex, pp. 167197.

HERNANDO DE LARRAMENDI, Miguel (2017): “España ante la independencia de Marruecos. La mirada de los diplomáticos" en Eloy Martín Corrales y Josep PichMitjana (eds.), España frente a la independencia de Marruecos, Barcelona, Bellaterra, pp. 163-190.

HERNANDO DE LARRAMENDI, Miguel y GONZÁLEZ GONZÁLEZ, Irene (2018): “Islam y colonialismo en la España contemporánea" en Julio de la Cueva, Miguel H. de Larramendi y Ana. I. Planet (eds.) Encrucijadas del cambio religioso en España: secularización, diversidad religiosa e Islam, Granada, Editorial Comares, pp. 143-170.

Historia de las Campañas de Marruecos,(1981a): Madrid, Servicio Histórico Militar. http://bibliotecavirtualdefensa.es/BVMDefensa/i18n/consulta/registro.cmd?id=1754 [consulta: 20/2/2020].

Historia de las Campañas de Marruecos,(1981b): Madrid, Servicio Histórico Militar. http://bibliotecavirtualdefensa.es/BVMDefensa/i18n/consulta/registro.cmd?id=1754_[consulta: 20/2/2020].

Historia de las Campañas de Marruecos,(1981c): Madrid, Servicio Histórico Militar. http://bibliotecavirtualdefensa.es/BVMDefensa/i18n/consulta/registro.cmd?id=1754_[consulta: 20/2/2020].

Historia de las Campañas de Marruecos,(1981d): Madrid, Servicio Histórico Militar. http://bibliotecavirtualdefensa.es/BVMDefensa/i18n/consulta/registro.cmd?id=1754 [consulta: 20/2/2020].

ORTEGA, Manuel L. (1922): "Una visita al Señor de la Montaña, cuatro días en la zona rebelde". Revista Hispano Africana, septiembre.

LAROUI, Abdallah (2012): Muŷmal-tārīj al-Magrib, Casablanca, Centro Cultural Árabe.

MARTíNEZ VÁZQUEZ, Daniel Agustín (1950): “Los gailanes", Selección de Conferencias y Trabajos realizados por la Academia de Interventores durante el curso 1949-50. Tetuán, Dirección de Asuntos Indígenas.

MATEO DIESTE, Josep Lluís (2002): "La paraetnografía militar colonial: poder y sistemas de clasificación social" en ÁngelesRamírez y Bernabé López García (coords)., Antropología y antropólogos en Marruecos, homenaje a David M. Hart, Barcelona, Edicions Bellaterra.

MATEO DIESTE, Josep Lluís (2003): La "hermandad" hispano-marroquí, política y religión bajo el Protectorado español en Marruecos (1912-1956), Barcelona, Bellaterra.

MAURA GAMAZO, Gabriel (1905): La cuestión marroquí según el punto de vista español, Editorial: M. Romero Impresor, Madrid.

RACHIK, Hassan (1992) : Le sultan des autres, rituel et politique dans le Haut Atlas, Casablanca, África Shark.

al-RĀYī, Muhammad (2013): Cuando los marroquíes vieron la figura del Rey Mohamed $V$ en la luna". Hespress. https://www.hespress.com/histoire/95239.html [consulta: 22/3/2020].

TAMSAMANI, Khallouk Abdelaziz (1999): País Yebala: Mezjen, España y Ahmad Raisúni.Granada, Editorial Universidad de Granada. 
VV. AA (1978 a): Encyclopédie de L'Islam, Brill, Leiden, L'Union Académique international

VELASCO DE CASTRO, Rocío (2002): "España ante la crisis del trono malaui: ¿unapolitica de oportunidades perdidas?" en Leandro Martínez Peñas, Manuela Fernández Rodríguez, David Bravo Díaz(coords.), La presencia española en África: del "Fecho de allende" a la crisis de perejil, pp. 131162. https://revistaaequitas.files.wordpress.com/2012/02/10-rocc3ado-velasco-de-castro.pdf [consulta: 2/4/2020].

VERNET GINÉS, Juan (1957):Historia de Marruecos, La islamización (681-1096),Tetuán, Instituto General Franco.

VILLANUEVA FAPRÓN, Jorge (2018): “Entre la colaboración y la insubordinación: la tariqaDarqawiyya de Marruecos ante Raisuni y Abdelkarim (1912-1927)", Revista de Historia Autónoma, 12, pp.152-169. DOI: http://dx.doi.org/10.15366/rha2018.12.008

ZARROUK, Mourad (2017): Clemente Cerdeira: intérprete, diplomático y espía al servicio de la Segunda República. Madrid, Editorial Reus. 